\title{
p53-mediated suppression of BiP triggers BIK-induced apoptosis during prolonged endoplasmic reticulum stress
}

\author{
Ignacio López ${ }^{1}$, Anne-Sophie Tournillon ${ }^{1}$, Rodrigo Prado Martins ${ }^{1}$, Konstantinos Karakostis ${ }^{1}$, Laurence Malbert-Colas ${ }^{1}$,
} Karin Nylander ${ }^{2}$ and Robin Fåhraeus ${ }^{*, 1,2,3}$

Physiological and pathological conditions that affect the folding capacity of the endoplasmic reticulum (ER) provoke ER stress and trigger the unfolded protein response (UPR). The UPR aims to either restore the balance between newly synthesized and misfolded proteins or if the damage is severe, to trigger cell death. However, the molecular events underlying the switch between repair and cell death are not well understood. The ER-resident chaperone BiP governs the UPR by sensing misfolded proteins and thereby releasing and activating the three mediators of the UPR: PERK, IRE1 and ATF6. PERK promotes G2 cell cycle arrest and cellular repair by inducing the alternative translated $p 53$ isoform p53 $\Delta$ N40 (p53/47), which activates 14-3-3 $\sigma$ via suppression of p2 ${ }^{\text {CDKN1A }}$. Here we show that prolonged ER stress promotes apoptosis via a p53-dependent inhibition of BiP expression. This leads to the release of the pro-apoptotic BH3-only BIK from BiP and activation of apoptosis. Suppression of bip mRNA translation is mediated via the specific binding of p53 to the first 346-nt of the bip mRNA and via a p53 trans-suppression domain located within the first seven N-terminal amino acids of p53 $\mathrm{N} 40$. This work shows how p53 targets BiP to promote apoptosis during severe ER stress and further illustrates how regulation of mRNA translation has a key role in p53-mediated regulation of gene expression during the UPR.

Cell Death and Differentiation (2017) 24, 1717-1729; doi:10.1038/cdd.2017.96; published online 16 June 2017

Stress to the endoplasmic reticulum (ER) impairs the folding capacity of the ER and leads to an accumulation and/or aggregation of misfolded or unfolded proteins which results in the induction of the unfolded protein response (UPR). ${ }^{1-3}$ This condition is observed during both physiological and pathological conditions, such as cancers.

In mammals, the canonical UPR pathway counts on three transmembrane proximal sensors: IRE1, PERK and ATF6. ${ }^{3}$ IRE1 splices out an intron from the $x b p-1$ mRNA which leads to the production of XBP-1 transcription factor. ${ }^{4-6}$ IRE1dependent RNA decay (RIDD) also degrades a subset of mRNAs coding for proteins trafficking through the ER. ${ }^{3,7}$ PERK phosphorylates the translation initiation factor elF2 $a$ resulting in general inhibition of cap-dependent translation. ${ }^{8}$ However, some mRNAs encoding proteins required for ER repair, such as ATF4 and p53, are activated by PERK. ${ }^{9-11}$ ATF6 controls the expression of genes with an ER stress response element (ERSE) including chaperones such as the ER-resident BiP (binding immunoglobulin protein or GRP-78 and HSPA5) and notably, XBP-1..$^{5,12-14}$ Together, these events aim to restore the balance between newly synthesized and mature proteins.

Extensive ER damage triggers a mitochondria-dependent apoptotic pathway mainly attributed to the activity of $\mathrm{CHOP}$ (C/EBP homologous protein, also named GADD153) which is downstream of ATF4. ${ }^{3,15}$ However, PERK or CHOP-deficient cells still undergo apoptosis during ER stress, indicating the existence of other pro-apoptotic events. ${ }^{16,17}$

$\mathrm{BiP}$ has a key role as a sensor and regulator of the UPR by binding and inhibiting the activity of PERK, IRE1 and ATF6. ${ }^{18,19}$ These associations are disrupted when misfolded proteins accumulate inside the ER. ${ }^{13}$ Expression of $\mathrm{BiP}$ requires sustained $m R N A$ translation mediated via regulatory elements present in both the $5^{\prime}$ UTR and ORF. ${ }^{20-22} \mathrm{BiP}$ represses apoptosis in several cell lines and in mice ${ }^{13,23}$ and this is related with direct and repressive interactions with caspases 7 and $12,{ }^{24}$ and with the BH3-only pro-apoptotic member of the BCL-2 family, BIK. ${ }^{25,26}$ In addition, BiP overexpression was described as an adaptive response to stress induced by cancer treatments. ${ }^{13}$

$\mathrm{BIK}$ is the founding member of the $\mathrm{BH} 3$-only proteins and it exists both as a free cytoplasmic and ER membrane-bound protein. ${ }^{27,28}$ BIK expression is regulated by $\mathrm{p} 53,{ }^{29,30}$ and controls apoptosis either directly by promoting oligomerisation of BAK and BAX at the ER membrane leading to ER membrane destablization and $\mathrm{Ca}^{2+}$ depletion ${ }^{31,32}$ or indirectly via releasing $B A X$, but not $B A K$, from $B C L-2$ and BCL-XL. ${ }^{27,28,33}$

p53 regulates the expression of various genes in response to different cellular insults. In response to DNA damage, p53 triggers $\mathrm{G} 1$ cell cycle arrest via induction of $p 21^{C D K N 1 A}$ or, if the damage is severe, apoptosis via pro-apoptotic factors

\footnotetext{
1Équipe Labellisée Ligue Contre le Cancer, Université Paris 7, INSERM UMR 1162 'Génomique Fonctionnelle des Tumeurs Solides', Paris, France; 'Department of Medical Biosciences; Umeå University, Umeå, Sweden and ${ }^{3}$ RECAMO, Masaryk Memorial Cancer Institute, Brno, Czech Republic

*Corresponding author: R Fåhraeus, Équipe Labellisée Ligue Contre le Cancer, Université Paris 7, INSERM UMR 1162 'Génomique Fonctionnelle des Tumeurs Solides', Institut de Génétique Moléculaire, 27 rue Juliette Dodu, Paris 75010, France. Tel: +33142499269; E-mail: robin.fahraeus@inserm.fr

Received 14.11.16; revised 18.4.17; accepted 09.5.17; Edited by J Bartek; published online 16.6.17
} 
such as $\mathrm{Bax}^{34-37}$ In the case of ER stress and activation of PERK, the translation initiation of the p53 mRNA switches from the full-length protein (p53FL) to the p53 $\mathrm{N} 40$ (p53/47) isoform. This isoform is initiated at the second in-frame AUG located 40 codon downstream of the first AUG via IRESdependent mechanisms. ${ }^{9,38,39}$ p53 N N40 lacks the first trans- a

$\bar{\alpha}$

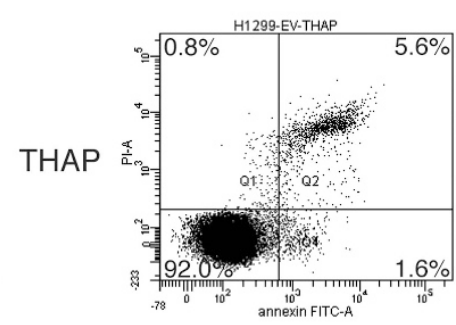

EV
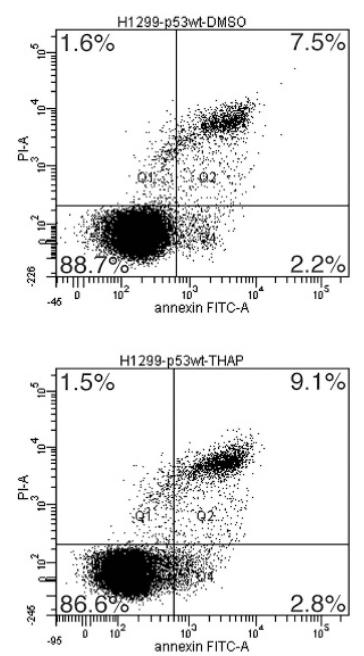

p53wt

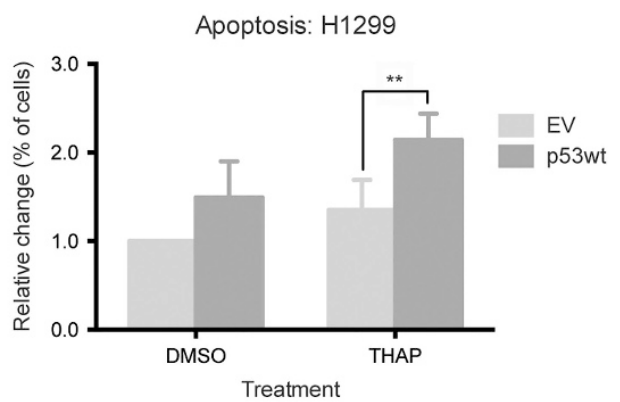

AnnexinV-FITC

c

b

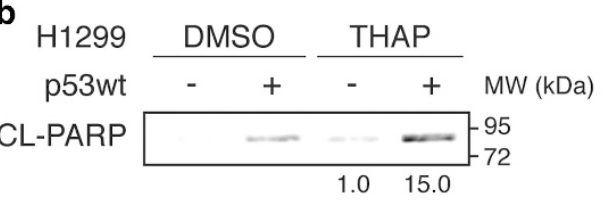

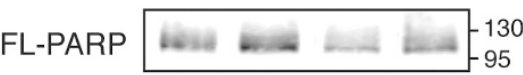
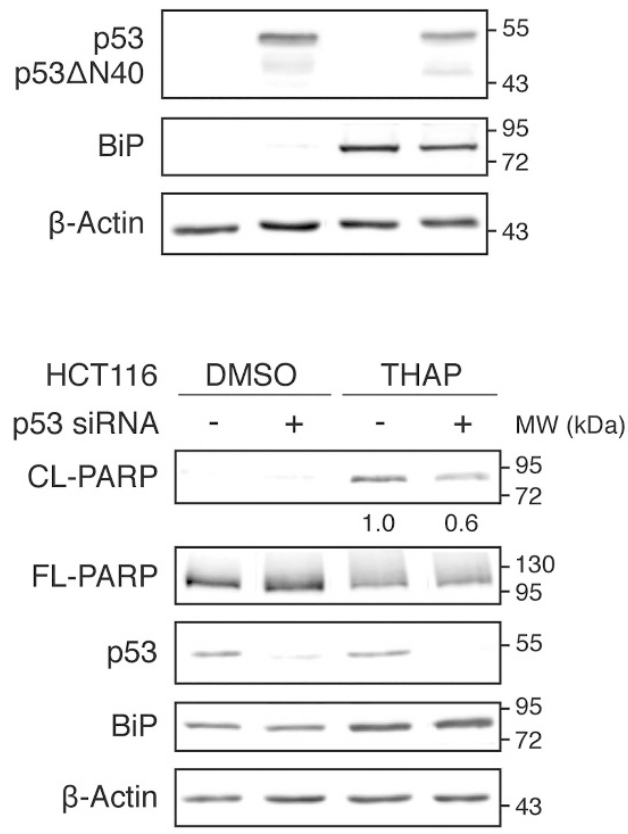

HCT116 p53wt

$\begin{array}{llllllllllll}\text { Time (h) } & 0 & 3 & 6 & 12 & 24 & 0 & 3 & 6 & 12 & 24 & \text { MW (kDa) }\end{array}$
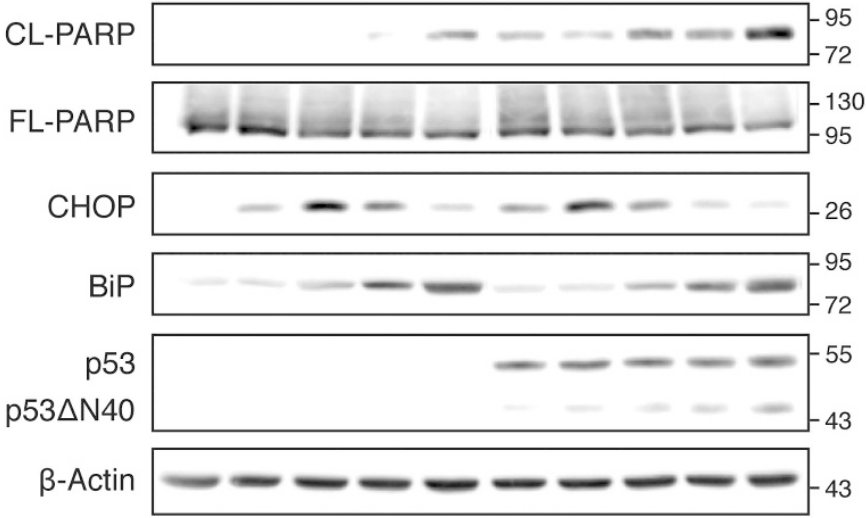

d

H1299

EV

p53wt

THAP $-\quad-\quad+\quad+\quad-\quad-\quad+\quad+$

CHOP SIRNA $-+-+-+-+\mathrm{MW}(\mathrm{kDa})$

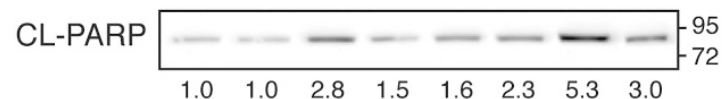

FL-PARP $--\square---130$
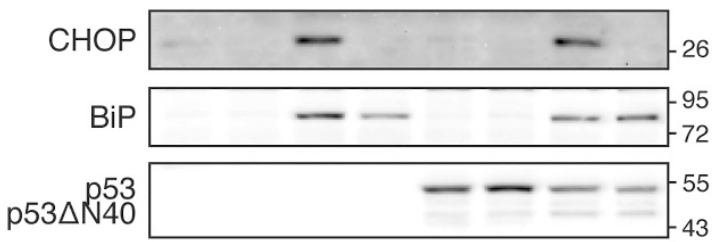

$\beta$-Actin -------43 
activation domain (TAD I) of p53 and actively suppresses the expression of $\mathrm{p} 21^{\mathrm{CDKN} 1 \mathrm{~A}}$ during $\mathrm{ER}$ stress by preventing p53FL-mediated induction of $p 21^{C D K N 1 A}$ transcription and by suppressing $p 21^{C D K N 1 A}$ mRNA translation, which promotes G2 cell cycle arrest. ${ }^{9,40}$ Other studies have implicated p53 in mRNA translation control and to the binding of $m d m x, f g f-2$, cdk4 and its own mRNAs, even though the physiological implications of these events are yet unknown. ${ }^{41-45}$

Here we set out to better understand the p53 pathway promoting apoptosis during ER stress. We show that prolonged $\mathrm{ER}$ stress releases $\mathrm{BIK}$ from $\mathrm{BiP}$ in a p53-dependent fashion. This requires the suppression of BIP synthesis via a direct interaction between p53 and a small region of the $5^{\prime}$ end of the CDS of the bip mRNA, in addition to a 7-aa region within the $\mathrm{p} 53$ trans-activation domain II (TAD II). These results further emphasize the important role of p53-mediated mRNA translation control during the UPR.

\section{Results}

p53 induces apoptosis during ER stress. We first established that p53 induces apoptosis during ER stress by treating cells with different concentrations of thapsigargin (THAP) that prevents $\mathrm{Ca}^{2+}$ uptake into the ER from the cytosol. ${ }^{46}$ A low dose of $50 \mathrm{nM}$ THAP for $24 \mathrm{~h}$ gave a measurable level of apoptosis using FACS analysis that correlates with detection of apoptotic markers by western blotting (see below). Early and late p53- and ER stressdependent apoptosis were determined using Annexin-V-FITC and propidium iodide (PI) in H1299 p53-null cells. Thapsigargin treatment alone induced $\mathrm{BiP}$ expression but did not generate a significant number of apoptotic cells. However, expression of p53 wild-type (p53wt) (300 ng of cDNA/ $1.75 \times 10^{5}$ seeded cells, $\left.0.15 \mu \mathrm{g} / \mathrm{ml}\right)$ in the presence of thapsigargin increased the level of apoptotic cells 1.6-fold as compared with the empty vector (EV)-transfected cells (Figures 1a and b, upper panel).

Induction of apoptosis was further analyzed by detection of caspase-mediated cleavage of PARP-1 using western blotting. ${ }^{47}$ Figure $1 \mathrm{~b}$ (upper panel) shows an increase in the 89-KDa fragment of PARP-1 (CL-PARP) in H1299 cells transfected with p53wt. A 15-fold increase in CL-PARP was observed in cells treated with thapsigargin and expressing p53wt, as compared with EV-transfected. Similar results were observed in cells treated with tunicamycin (TUN), a drug causing ER stress by inhibiting $\mathrm{N}$-linked glycosylation ${ }^{48}$
(Supplementary Figure 1a). siRNA against p53 in HCT116 p53-positive cells resulted in a $40 \%$ reduction in thapsigargininduced cleavage of PARP-1 (Figure 1b, lower panel). Similar results were obtained using p53-positive A549 cells (Supplementary Figure 1b).

We addressed the kinetics of the induction of apoptosis and Figure 1c shows CL-PARP $24 \mathrm{~h}$ post-treatment in the absence of p53. Expression of p53 alone ( $0 \mathrm{~h}$ THAP treatment) was sufficient to detect CL-PARP and the synergistic effect of p53 and ER stress on CL-PARP expression could be observed after $6 \mathrm{~h}$, and longer, of THAP treatment. This indicates that p53 and ER stress together potentiate the induction of apoptosis. ER stress-induced apoptosis is commonly attributed to the activity of $\mathrm{CHOP}^{3,15}$ Interestingly, CHOP expression was detected $3 \mathrm{~h}$ post-THAP treatment and peaked at $6 \mathrm{~h}$, before gradually decreasing to non-measurable levels at $24 \mathrm{~h}$. This expression pattern was not affected by p53 (Figure 1c). Even though CHOP levels peaked at $6 \mathrm{~h}$, CL-PARP was not observed before $24 \mathrm{~h}$ unless p53 was expressed. When we downregulated CHOP by siRNA, there was only a limited induction of apoptosis in p53-null cells following thapsigargin treatment (Figure 1d). However, cells expressing p53 displayed a 3-fold increase of p53- and ER stress-dependent PARP-1 cleavage in the absence of CHOP, compared with cells transfected with control SiRNA and treated with DMSO (Figure 1d).

BiP prevents ER stress- and p53-induced apoptosis. In previous work and during this study, we have observed a small but consistent reduced induction of $\mathrm{BiP}$ protein expression $(25 \% \pm 10)$ following thapsigargin treatment in the presence of p53 (Figure 1b, upper panel). ${ }^{40}$ As BiP has been shown to have an anti-apoptotic effect in both cell lines and in mice, ${ }^{13,23}$ we tested if suppression of BiP induction can help explain p53's capacity to enhance ER stress-induced apoptosis. We first knocked-down BiP using siRNA and observed a 1.4- and 1.7-fold increase in apoptosis in p53-negative (H1299) and p53-positive (HCT116) cell lines treated with $50 \mathrm{nM}$ thapsigargin for $24 \mathrm{~h}$, as determined using FACS analysis (Figure 2a; Supplementary Figures $2 \mathrm{a}$ and b). BiP knock-down in DMSOtreated cells did not result in any significant change in apoptosis. Downregulation of BiP induced CL-PARP expression (7- and 2-fold) in thapsigargin-treated H1299 and HCT116 cells, respectively (Figure $2 \mathrm{~b}$ ).

We next tested whether the p53-dependent induction of apoptosis during ER stress depends on BiP expression levels.

Figure 1 p53 induces apoptosis during prolonged ER stress. (a) p53-null non-small cell lung carcinoma H1299 cell line expressing, or not, p53wt were treated with DMSO or $50 \mathrm{nM}$ of thapsigargin (THAP) for $24 \mathrm{~h}$ and analyzed for apoptosis by flow cytometry after staining with Annexin V-FITC and propidium iodide (PI). Representative dot plots show the discrimination of viable cells (FITC - PI - , Q3), early apoptotic (FITC+ PI - , Q4) and late apoptotic or necrotic cells (FITC+ Pl+, Q2). The percentage shown on each quadrant represents the number of cells in each group compared with the parent population considered for the analysis. Histogram shows the relative change in percentage of cells in early and late apoptosis/necrosis compared with empty vector (EV)-transfected and DMSO-treated cells, set to 1 (mean \pm S.D., $n=5$ ). Two-tailed paired t-test compared data as indicated, ${ }^{* *} P<0.01$. (b) H1299 cells were transfected as indicated. The p53wt colon carcinoma HCT116 cell line was treated, or not, with siRNA against p53. Western blots show the levels of cleaved PARP-1 (85-kDa fragment; CL-PARP) as an apoptotic marker. p53 isoforms were detected by ACMDD serum. ${ }^{40,57}$ BiP was used as a positive control for UPR activation and $\beta$-actin as a loading control. Numbers below the blots correspond to relative quantification by densitometry compared with the reference point set to 1. (c) H1299 cells expressing, or not, p53wt were incubated with $50 \mathrm{nM}$ thapsigargin (THAP) at indicated times. Levels of pro-apoptotic CHOP and apoptotic marker CL-PARP were detected by western blotting during indicated time points. Numbers below the blots correspond to relative quantification by densitometry compared with the reference point set to 1. (d) H1299 cells as in Figure 1a were transfected with siRNA targeting CHOP or control siRNA. Downregulation of CHOP was confirmed by western blotting and its effect on apoptosis induction was assessed by detection of CL-PARP. FL-PARP confirmed PARP-1 expression levels are not significantly affected. For all, western blots represent $n \geq 2$ 

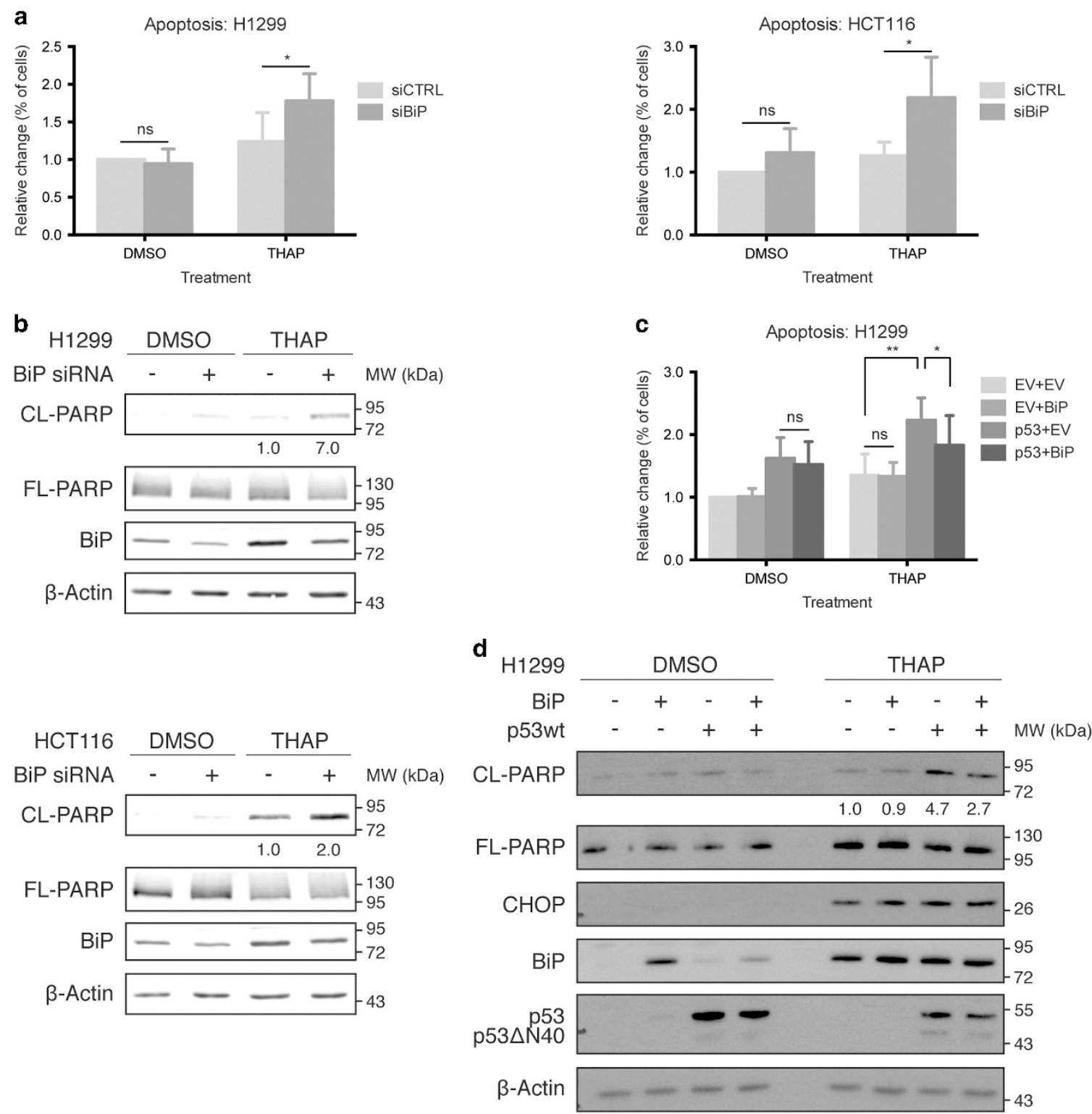

Figure 2 BiP prevents ER stress- and p53-induced apoptosis. (a) p53-null H1299 or p53-proficient HCT116 cells transfected with siRNA against BiP or control siRNA were treated as in Figure 1a and analyzed by FACS. Histograms show the relative change in percentage of cells in early and late apoptosis/necrosis compared with control siRNAtransfected and DMSO-treated cells, set to 1 (mean \pm S.D., $n=4$ ). Two-tailed paired $t$-test compared data as indicated, ${ }^{*} P<0.05$; ns, not significant. (b) H1299 and HCT116 cell lines were transfected or not with siRNA against BiP or control and treated as in Figure 2a. Levels of apoptotic marker CL-PARP and BiP were detected by western blotting. Numbers below the blots correspond to relative expression levels compared with the reference point set to 1. (c) Apoptosis induction was analyzed in $\mathrm{H} 1299$ transfected with BiP and/or p53wt, treated and stained with FITC and PI as described in Figure 1a. Histograms show the relative change in percentage of cells in early and late apoptosis/necrosis compared with EV-transfected and DMSO-treated cells, set to 1 (mean \pm S.D., $n=5$ ). Two-tailed paired t-test compared data as indicated, ${ }^{*} P<0.05$, ${ }^{* *} P<0.01$, ns non-significant. (d) Apoptosis induction was estimated by CL-PARP levels in $\mathrm{H} 1299$ treated as in Figure 1c. The pro-apoptotic CHOP shows no significant variation. Numbers below the blots correspond to relative quantification by densitometry compared with the reference point set to 1 . For all, blots represent $n \geq 2$

Figure 2c (Supplementary Figure 2c) show that BiP expression alone did not change the level of apoptosis under normal conditions or during ER stress. However, the p53-dependent apoptosis observed during prolonged ER stress conditions was counteracted by approximately $50 \%$ following BiP overexpression. Importantly, p53-dependent apoptosis in the absence of ER stress was not affected by overexpression of BiP. CL-PARP levels were down by $40 \%$ in cells expressing
$\mathrm{BiP}$ - and p53wt, as compared with cells expressing p53wt only (Figure 2d).

p53 controls synthesis of BiP. We next investigated what lies behind the observed inverse correlation between p53 and BiP expression. Increasing amounts of exogenous p53wt in cells treated with $50 \mathrm{nM}$ thapsigargin for $24 \mathrm{~h}$, resulted in a dose-dependent downregulation of endogenous $\mathrm{BiP}$ 
a

a1299
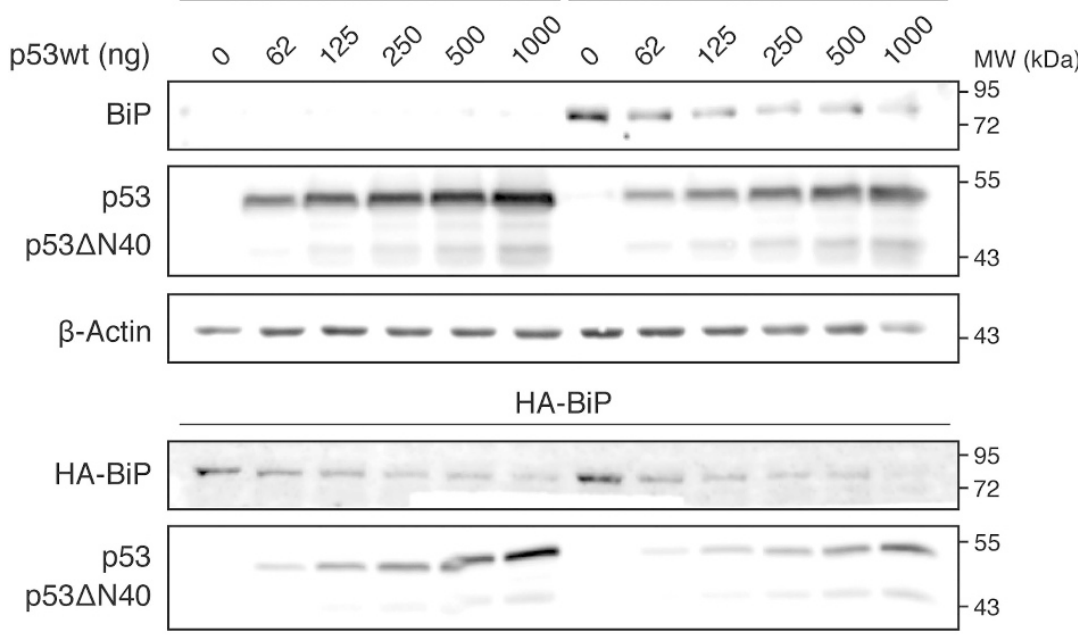

$\beta$-Actin

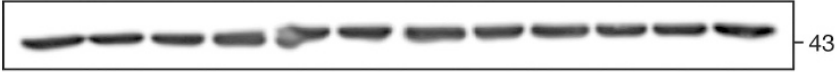

c

H1299

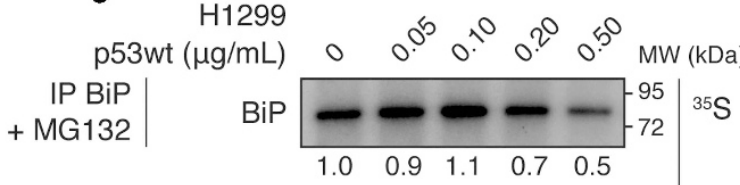

Input
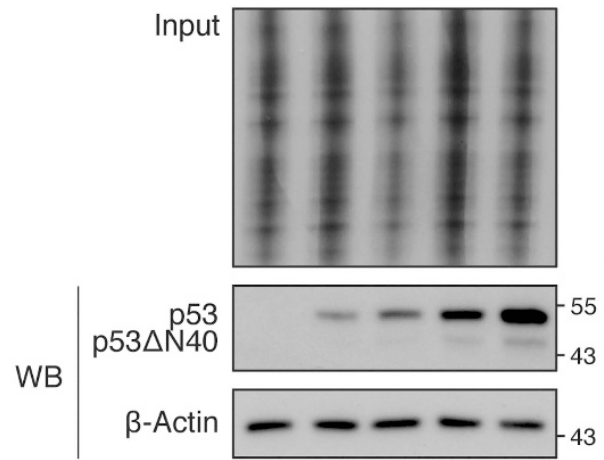

b

bip mRNA expression: $\mathrm{H} 1299$

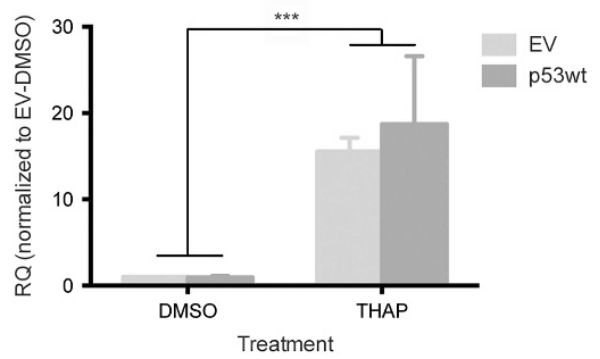

ha-bip mRNA expression: H1299
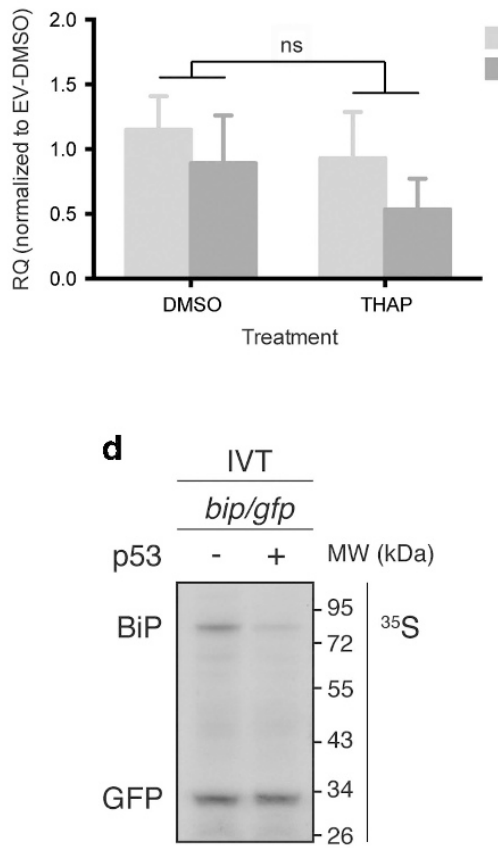

Figure 3 p53 controls BiP protein synthesis. (a) Expression levels of endogenous BiP and exogenous HA-tagged BiP were studied in H1299 cells expressing increasing amounts of p53wt cDNA and treated with $50 \mathrm{nM}$ thapsigargin (THAP) or DMSO for $24 \mathrm{~h}$. HA-BiP expression was differentiated from the endogenous BiP by the use of an antibody against the HA-tag. CM-1 sera was used to detect p53 isoforms. (b) Expression of endogenous bip or exogenous ha-bip mRNAs were quantified using relative RT-qPCR in H1299 cells transfected or not with p53wt cDNA and treated as in Figure $3 a$. Values of bip and ha-bip were normalized against $\beta$-actin and GFP, respectively, and are presented as fold change relative to EV-transfected and DMSO-treated cells, set to 1 (mean \pm S.D., $n=3$ performed in duplicates). Two-way ANOVA compared data of the effect of treatment and transfection of p53wt on bip and ha-bip mRNAs expression as indicated, ${ }^{* *} \mathrm{P}<0.01$; ns, non-significant. (c) De novo BiP protein synthesis. H1299 expressing increasing amounts of p53wt cDNA and incubated with $50 \mathrm{nM}$ thapsigargin (THAP) for $24 \mathrm{~h}$ were metabolically pulse labeled with ${ }^{35} \mathrm{~S}$-Met for 20 min in the presence of proteasome inhibitor MG132. Cell extracts were immunoprecipitated (IP) with BiP antibody and levels of IP radiolabelled protein were assessed by autoradiography. Input samples served as control for equal incorporation of ${ }^{35} \mathrm{~S}$-Met into cellular proteins. Western blots show increasing expression of p53 isoforms detected with $\mathrm{CM}-1$ sera. Numbers below the autoradiography correspond to relative quantification compared with the reference point set to 1 . Autoradiograph and western blotting shown are representative of $n \geq 2$. (d) In vitro translation of bip and gfp mRNAs in the presence of p53. A recombinant p53 protein was pre-incubated with a mixture of in vitro-synthesized bip and control gfp mRNAs for 15 min at $37^{\circ} \mathrm{C}$ before translation was initiated at $30^{\circ} \mathrm{C}$ for $1.5 \mathrm{~h}$ using rabbit reticulocyte extract in the presence of ${ }^{35} \mathrm{~S}$-Met. Level of radiolabelled proteins were assessed by autoradiography. Autoradiograph shown is representative of $n=3$

(Figure 3a, upper panel). When we introduced an exogenous HA-tagged BiP construct consisting on the CDS only, we observed a p53 dose-dependent suppression of HA-BiP expression using anti-HA antibody (Figure 3a, lower panel). Using RT-qPCR, we confirmed that neither bip nor ha-bip mRNA levels were affected by p53 under normal nor ER stress conditions (Figure 3b).
A 20-min pulse with ${ }^{35} \mathrm{~S}$-Met in the presence of the proteasome inhibitor MG132, revealed an 45\% downregulation of BiP synthesis at $0.5 \mu \mathrm{g} / \mathrm{ml}$ of p53wt cDNA (1.25 $\mu \mathrm{g} /$ $1.75 \times 10^{5}$ of seeded cells) (Figure $3 \mathrm{c}$ ). We also evaluated the rate of $\mathrm{BiP}$ protein synthesis in an in vitro system using a recombinant purified p53 protein (Supplementary Figure 3) together with in vitro transcribed capped bip and control gfp 


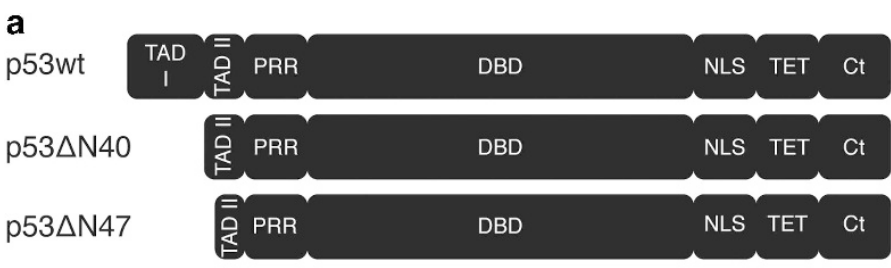

b

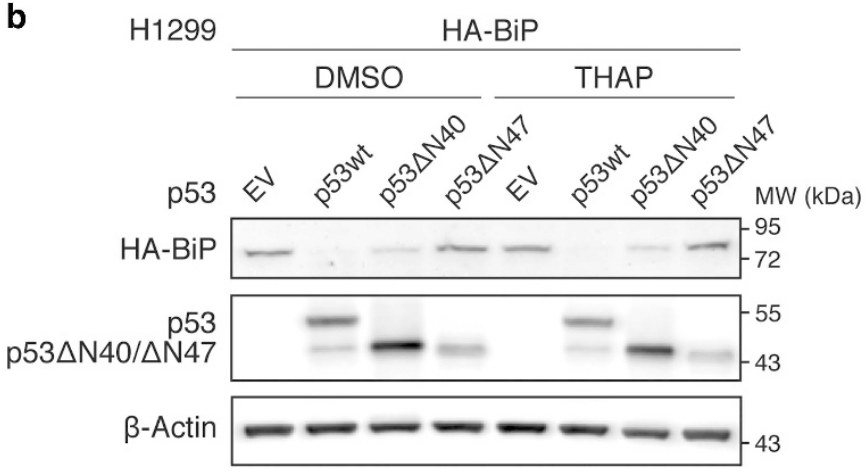

C ha-bip mRNA expression: $\mathrm{H} 1299$

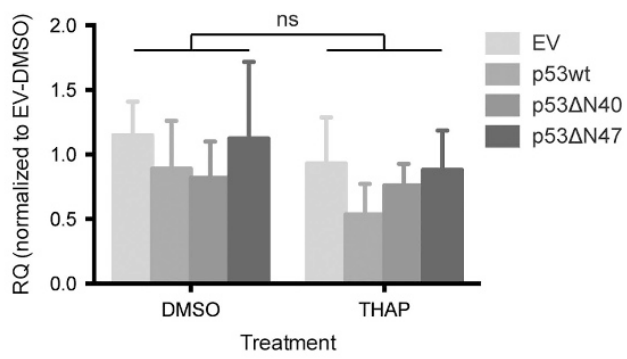

d

H1299 DMSO $\longrightarrow$ THAP

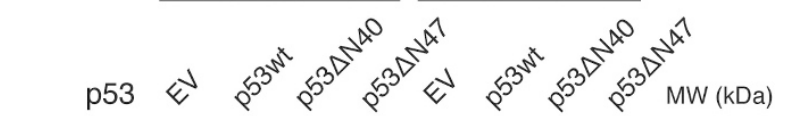

CL-PARP

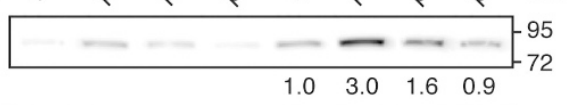

FL-PARP

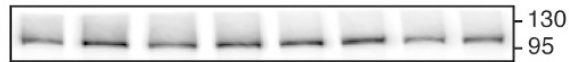

$\mathrm{p} 53 \Delta \mathrm{N} 40 / \Delta \mathrm{N} 47$

$\beta$-Actin
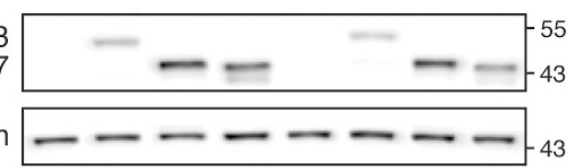

Figure 4 A p53 mRNA trans-suppressor domain located at aa 40-47. (a) Cartoon representing the p53 isoforms and deletion mutant used to localize the region involved in controlling BiP expression. p53 wild-type (p53wt) cDNA encodes for both p53 full-length (FL) and p53 N40 isoforms. p53 $\Delta$ N40 (also known as p53/47) lacks the first 39 aa of p53FL. p53 $\Delta$ N47 lacks the first 7 aa of p53 $\Delta$ N40. TAD; trans-activation domain I and II, PRR; Proline-rich region, DBD; DNA-binding domain, NLS; nuclear localization signal, TET; tetramerization domain, Ct; Carboxi-terminal regulatory domain. (b) p53wt and p53 N N40 isoforms, but not p53 NN47, reduce the expression of HA-BIP. H1299 cells expressing different p53 cDNA constructs together with HA-tagged BiP and treated with $50 \mathrm{nM}$ thapsigargin (THAP) or DMSO. (c) Expression of exogenous ha-bip mRNAs was quantified using relative RT-qPCR in H1299 cells expressing different p53 cDNA constructs and treated as in Figure 4b. Values of ha-bip were normalized against GFP and are presented as fold change relative to EV-transfected and DMSO-treated cells, set to 1 (mean \pm S.D., $n=3$ performed in duplicates). Two-way ANOVA compared data of the effect of treatment and transfection of p53 on ha-bip mRNA expression as indicated, ${ }^{* \star} P<0.01$; ns, non-significant. (d) Induction of apoptosis was indirectly determined by analysing the amount of CL-PARP detected by western blotting. Numbers below the blots correspond to relative quantification by densitometry compared with the reference point set to 1 . For all, blots represent $n \geq 2$

mRNAs. The mRNAs were pre-incubated with, or without, p53 protein before the in vitro translation was performed. ${ }^{45}$ Figure $3 d$ shows that while GFP synthesis was not modified by the presence of $\mathrm{p} 53$, the synthesis of BiP was reduced by $70 \%$. Hence, p53's negative effect on bip mRNA translation does not require p53-mediated control of gene transcription nor post-translational modifications by UPR pathways.

p53 full-length and p53 $\Delta \mathrm{N} 40$ control BiP expression. We have previously shown that the TAD II domain of p53 has a role in controlling translation of the $m d m x$ mRNA. ${ }^{45}$ We therefore decided to test the effect of the natural p53 isoform p53 $\triangle \mathrm{N} 40$ along with different $\mathrm{N}$-terminal deletion mutants on BiP expression, in order to identify a putative p53 domain controlling this activity (Figures $4 a$ and b; Supplementary Figure 4a). p53 $\Delta \mathrm{N} 40$ and p53wt downregulated HA-tagged BiP during both normal and ER stress scenarios, adding to the argument that the capacity to control BiP expression does not require ER stress-dependent activation of p53 (Figure 4b; Supplementary Figure $4 a$ and b). However, deletion of 7 aa (p53 $\Delta$ N47) adjacent to the initiation site for p53 $\Delta \mathrm{N} 40$, abolished the suppression of HA-BiP (Figure 4b) while deletion of a smaller region ( $p 53 \Delta N 43$, Supplementary
Figure 4a) and point mutants (not shown) showed intermediate effects. RT-qPCR confirmed that exogenous ha-bip mRNAs levels were not affected by the p53 constructs (Figure 4c).

We then analyzed the effect of these three p53 constructs on apoptosis induction by looking at CL-PARP levels. While expression of p53 $\triangle \mathrm{N} 47$ did not modify the levels of CL-PARP in cells treated with DMSO or with $50 \mathrm{nM}$ thapsigargin for $24 \mathrm{~h}$, p53wt and p53 $\triangle$ N40 induced CL-PARP both in normal and stress conditions (Figure $4 d$ ). These results indicate a direct correlation between p53-mediated trans-suppression of $\mathrm{BiP}$ expression and p53-induced apoptosis during ER stress.

p53 binds the coding sequence of bip mRNA. We and others have shown that p53 binds to a selected set of mRNAs to control their translation. ${ }^{41-45}$ In order to test if a complex exists between p53 and the endogenous bip mRNA in cellulo, we used the proximity ligation assay (PLA). A 25 nt DNA oligo corresponding to $n t+1010$ to +1029 of the bip mRNA coupled with digoxigenin at its $3^{\prime}$ end was hybridized with the bip mRNA on fixed cells. We then used an anti-digoxigenin mouse monoclonal antibody together with $\mathrm{CM}-1$ rabbit antip53 sera and detected the bip mRNA-p53 protein complexes 
in the nucleus and cytoplasm using full-length, p53 $\Delta \mathrm{N} 40$ and p53 $\Delta$ N47 p53 constructs. The number of complexes detected in the three cases is similar, thus suggesting that the capacity of p53 to interact with the mRNA is not affected by the $\mathrm{N}$-terminal deletions performed within this study. The CM-1 polyclonal sera detected all three p53 proteins predominantly a
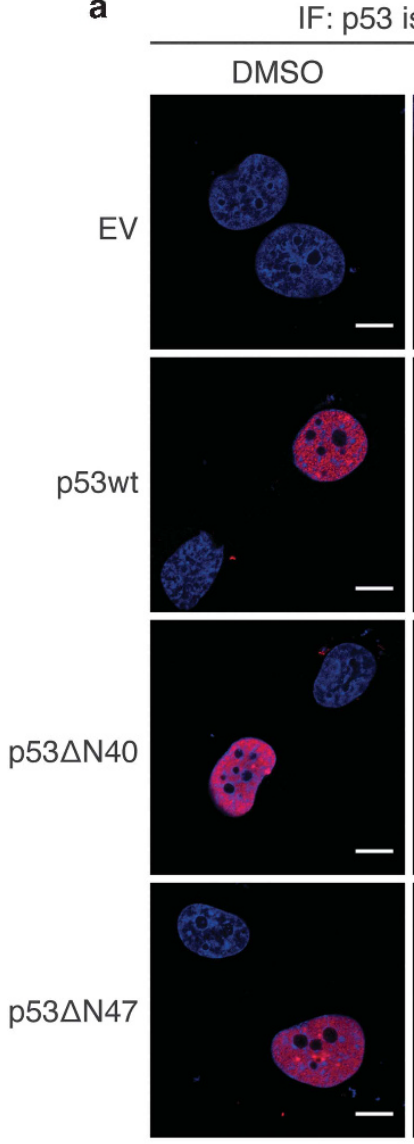

b
PLA: bip mRNA/p53 isoforms
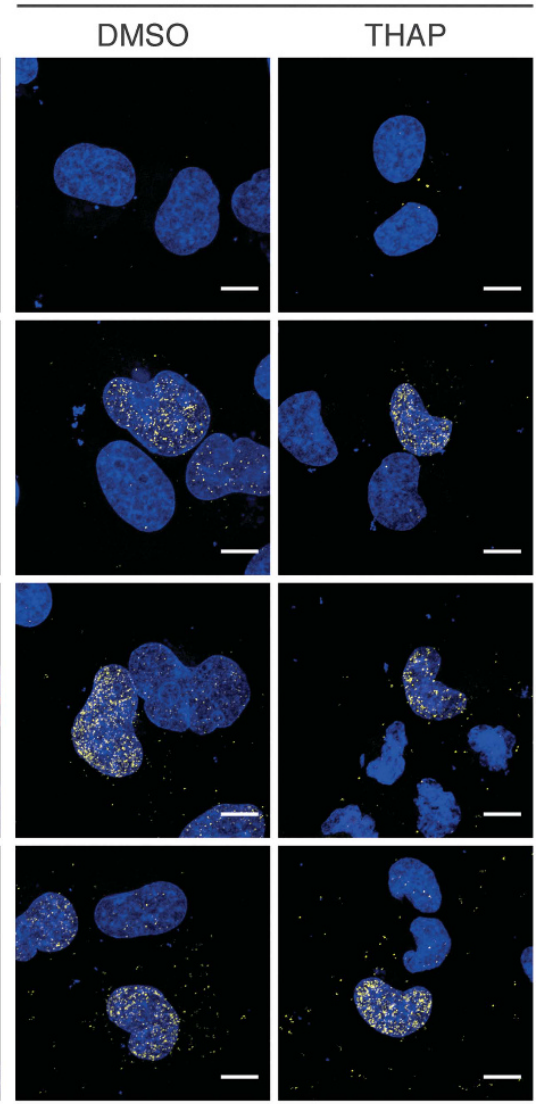

bipFL (CDS): $1965 \mathrm{nt}$

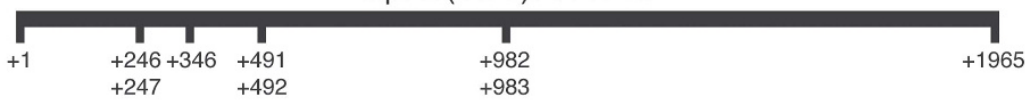

Binding: p53-bip mRNA

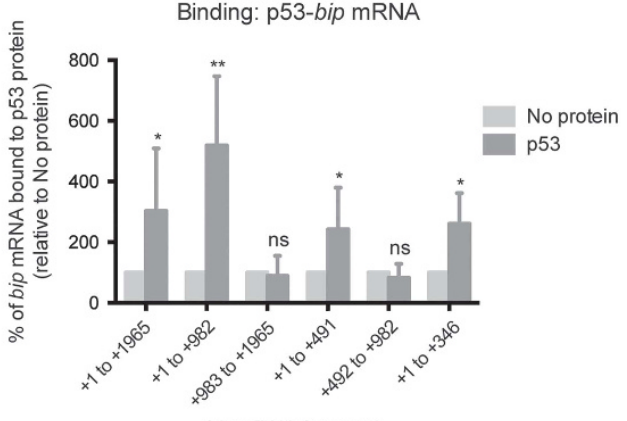

bip mRNA fragment

Figure 5 p53 binds to the +1 to +346 sequence of the bip mRNA. (a) Immunofluorescence (IF) of p53 protein (left panels, red signal) and proximity ligation assay (PLA) (right panels, bright yellow dots) between p53 and bip mRNA in H1299 cells expressing indicated constructs and treated with $50 \mathrm{nM}$ thapsigargin (THAP) for $24 \mathrm{~h}$. IF and PLA were performed with CM-1 rabbit antibody against p53. For the PLA, a mouse antibody against a digoxigenin-labeled DNA against bip mRNA was used together with CM-1. The scale bar corresponds to $10 \mu \mathrm{m}$. Images are representative of $n \geq 10$ cells obtained in two independent experiments. See also Supplementary Figure $5 \mathrm{a}$ for PLA controls. (b) In vitro protein-RNA co-immunoprecipitation shows the specific interaction between p53 and the first 346 -nt the $5^{\prime}$ coding sequence of the bip mRNA. Upper panel shows the different regions of bip mRNA that were cloned and used to generate mRNA in vitro to assess their capacity to interact with p53. Lower panel shows the quantification of different bip mRNAs bound to $p 53$ as determined by RT-qPCR. Data is presented as percentage of RNA bound to p53 and represents the ratio between the RNA bound to p53 and the total RNA (bound+unbound) and normalized to the corresponding no protein control that was set to $100 \%$ (mean \pm S.E.M., $n \geq 3$ performed in triplicates). Two-tailed unpaired $t$-test compared data to the corresponding reference point, ${ }^{*} P<0.05,{ }^{* \star} P<0.01$; ns, non-significant 
in the nucleus when analyzed by immunofluorescence (IF). As expected, H1299 cells lacking p53 (EV-transfected) were negative for the IF and showed a few PLA dots attributed to experimental background, demonstrating the specificity of the PLA assay (Figure 5a; Supplementary Figure 5a).

We next tested if there is a direct interaction between p53 and the bip mRNA. Recombinant purified p53 protein (Supplementary Figure 3) was incubated together with truncated in vitro-synthesized bip mRNAs before anti-p53 DO1 monoclonal antibody was added. Following immunoprecipitation, the bip mRNA bound to p53 and the unbound fractions were quantified by RT-qPCR and the ratio bound/ unbound was calculated. This revealed that p53 interacted directly with the full-length CDS of the bip mRNA $(+1$ to +1965$)$ and more specifically to the first 491 nts of the CDS $(+1$ to +491 ) (Figure $5 b$ ). We further narrowed the interacting region to the +1 to +346 fragment of the CDS (Figure 5b; Supplementary figure $5 \mathrm{~b}$ ). None of the mRNAs lacking the first 346 nts bound to p53.

We then tested if the +1 to +346 bip mRNA sequence is sufficient to mediate the interaction with p53 protein in cellulo. We generated two reporter constructs where the +1 to +346 or +346 to +1965 sequences of the bip mRNA were fused to GFP (bip(1-346)-GFP and bip(346-1965)-GFP, respectively). These constructs were transfected into $\mathrm{H} 1299$ cells together with p53 isoforms (Figure 4a) and their localization was analyzed by IF using a digoxigenin-labeled GFP probe (nt +386 to +413 ). Figure 6 a shows that both reporter mRNAs were similarly expressed and distributed and that their localizations were not modified by the presence of different p53 isoforms. However, PLA using the GFP RNA probe and anti-p53 polyclonal CM-1 sera detected the bip(1-346)-GFP in complex with all three p53 proteins in the nucleus and cytoplasm but failed to show the RNA-protein complex using the bip(346-1965)-GFP mRNA (Figure 6a). PLA on cells expressing EV were negative for both reporter mRNAs.

A silent bip(1-346)-GFP reporter construct (AUGs in the bip mRNA segment were mutated to GCG (Ala) codons) was expressed in $\mathrm{H} 1299$ cells in the presence of different p53 constructs. This revealed an $\sim 70 \%$ and $40 \%$ suppression of GFP expression using p53wt and p53 $\Delta \mathrm{N} 40$, respectively, when compared with the EV- or p53 $\Delta \mathrm{N} 47$-transfected cells. The effect on GFP expression alone using the $\mathrm{p} 53$ isoforms resulted in an average suppression of $10 \%$ (Figure $6 \mathrm{~b}$ ). These results show that the first 346-nt of the bip mRNA CDS interact with p53 and are sufficient for p53-mediated mRNA translation control.

p53 induces BIK levels and prevents its interaction with BiP. We next set out to determine the mechanism whereby reduced $\mathrm{BiP}$ levels induced cell death. We focused on the BiP-interacting pro-apoptotic protein BIK. The BiP/BIK interaction takes place at the ER membrane and has been suggested to prevent BIK from activating BAX.25,26,31,33 We first observed, as reported, that p53wt induces bik mRNA levels (Figure $7 a$ ). ${ }^{29,30}$ This was observed both under normal and ER stress conditions and, interestingly, the p53 $\triangle \mathrm{N} 40$ and p53wt isoforms induced Bik transcription to the same level, an observation that has not been described previously. However, p53 $\triangle \mathrm{N} 47$ did not affect bik levels. The bik mRNA levels were mirrored by the BIK protein levels (Figure $7 \mathrm{~b}$ ). However, BIK protein levels were overall suppressed during ER stress, presumably due to the effect of phosphorylated elF2a.

We next studied the BiP/BIK protein interaction under normal and ER stress conditions. IF indicates that BIK is located in the cytoplasm and that the sub-cellular distribution was not greatly affected by ER stress (Figure 7c). The interaction between BIK and BiP was then assessed by PLA using anti-BIK mouse monoclonal and anti-BiP rabbit polyclonal antibodies. In order to determine the endogenous BIK/ BiP complex in cells expressing p53, we carried out a BIK-BiP PLA and at the same time used a p53 antibody (1801) coupled to Alexa Fluor 488. The BiP/BIK complex was detected in the cytoplasm and was, interestingly, not affected by ER stress. This suggests that the basal levels of $\mathrm{BiP}$ are sufficient to sequester BIK under non-ER stress conditions when the amount of misfolded proteins in the ER is low. The presence of p53 did not have any effect on the BIK/BiP complex in normal conditions. Interestingly, we observed a sharp decrease in $\mathrm{BiP} / \mathrm{BIK}$ interactions in cells treated with thapsigargin and expressing p53wt, as shown by the ratio of PLA BIK/BiP complexes in p53-positive/p53-negative cells (1.3 and 0.4 in DMSO and THAP, respectively) (Figure 7d). Importantly, overexpression of increasing amounts of exogenous BiP restored the $\mathrm{BiP} / \mathrm{BIK}$ interaction in p53wt-expressing and ER-stressed cells (ratio PLA BIK/BiP complexes in p53-positive/p53-negative of 0.8 and 1.0 when 50 and $100 \mathrm{ng}$ of BiP were co-expressed, respectively) (Figure 7d). These data indicate that the levels of BiP expression alone during ER stress determine the interaction with BiK.

\section{Discussion}

Solid tumors usually have a constitutive activated UPR and therefore, they are more sensitive to proteasome inhibitors used as cancer drugs, like bortezomib. ${ }^{3,49}$ However, the molecular mechanisms responsible for ER stress-induced apoptosis are still relatively unclear. Like with the DNA damage response pathway, cells strive towards cell cycle arrest and repair following ER stress. ${ }^{3,9}$ However, in the presence of severe DNA damage or ER stress, the cells switch towards pro-death pathways. ${ }^{3,16}$ Both the cell cycle arrest/ repair and the pro-apoptotic pathways following these two different damages are partially controlled by p53 but via different mechanisms of action. While p53-dependent control of gene expression during DNA damage relies on transcription, regulation of mRNA translation is favored during the UPR.

ER stress-induced apoptosis has commonly been attributed to CHOP. However, CHOP-deficient cells still undergo apoptosis indicating the existence of additional checkpoints and signaling events mediating cell death. ${ }^{16,17}$ In this study, we observed a synergistic pro-apoptotic effect of prolonged ER stress and p53 that does not appear to involve CHOP. Instead, the p53-mediated induction of apoptosis is linked to a suppression of bip mRNA translation and the dissociation of the $\mathrm{BIK} / \mathrm{BiP}$ complex. It is interesting to notice that even though the suppression of BiP levels by p53 are not too imposing, it is sufficient to completely disperse the BiP/BIK complex. This is presumable related to the fine balance between the interaction between BiP and its ER stress sensors on the one hand and misfolded proteins on the other. 
a
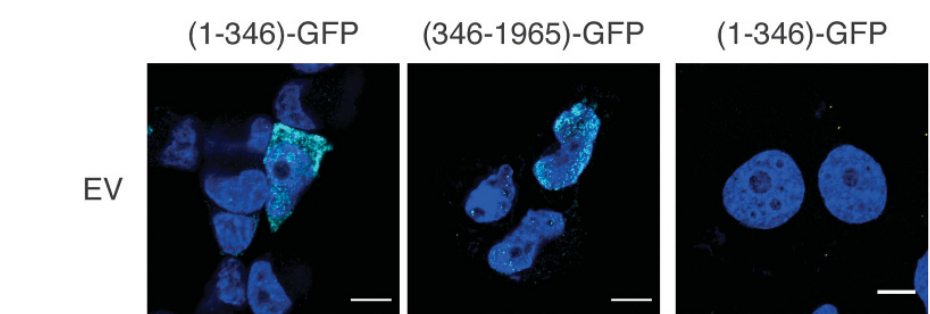

\section{(346-1965)-GFP}

p53wt
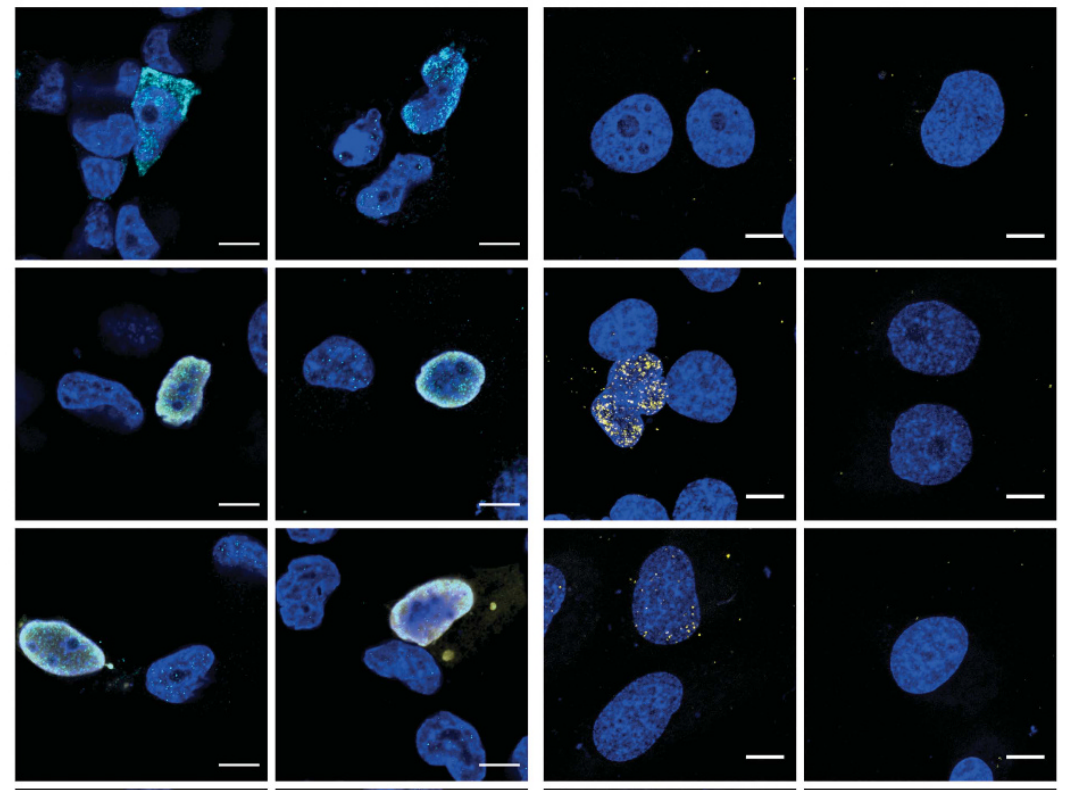

p53 $\Delta N 40$
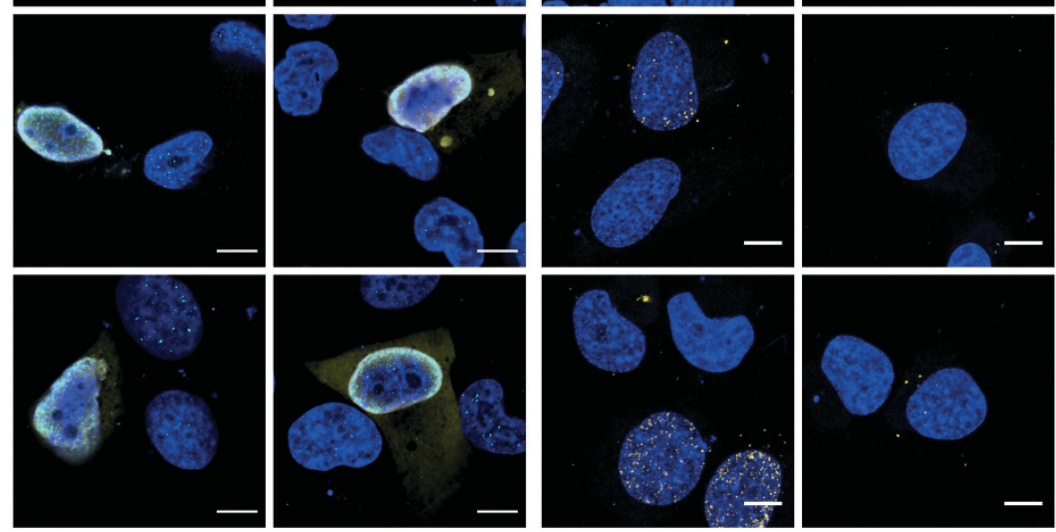

p53 $\Delta$ N47

b

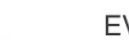

EV GFP
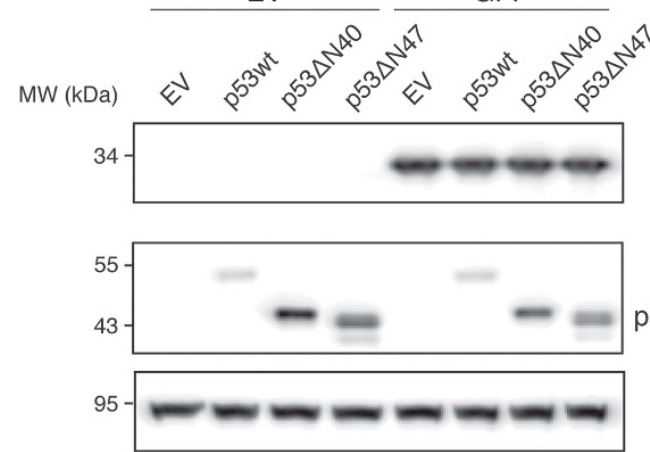

p53

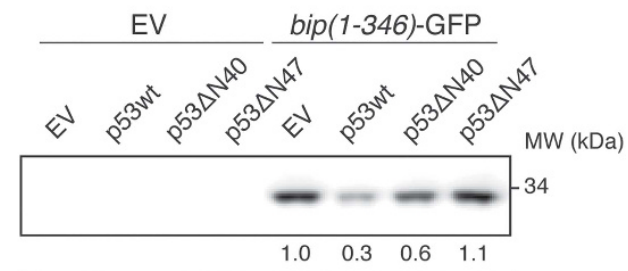

p53

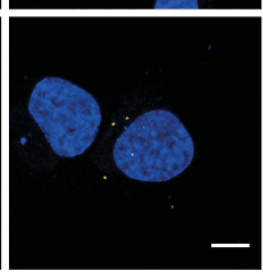

p53

GFP

$553 \Delta N 40 / \Delta N 47$

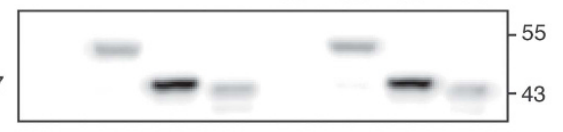

HSP90a $+\beta$

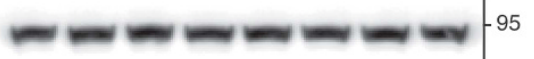

Figure 6 The first 346 nucleotides of the bip mRNA coding sequence mediates p53-dependent control of expression. (a) IF (p53 olive signal and bip-GFP mRNA magenta signal) and PLA (yellow dots) of p53 isoforms and bip-GFP mRNA reporter constructs in H1299 cells under normal conditions. IF and PLA were performed with anti-p53 CM-1 rabbit sera and a mouse antibody against a digoxigenin-labeled GFP DNA probe. The scale bar corresponds to $10 \mu \mathrm{m}$. Images are representative of $n \geq 10$ cells obtained in two independent experiments. (b) p53 isoform-dependent control of GFP expression from reporter construct bip(1-346)-GFP. H1299 expressing either GFP or bip(1-346)-GFP (bip mRNA lacks in-frame AUG and only expresses GFP) together with indicated p53 constructs. GFP expression was analyzed by western blotting. HSP90 $\alpha+\beta$ was used as a loading control. Numbers below the blots correspond to relative quantification by densitometry compared with the reference point set to 1 . Blot shown is representative of two independent experiments

The BiP/BIK complex has been reported to be at the ER membrane. ${ }^{25,26}$ It is, however, not clear if this interaction is direct, or not, and the proximity assay used here only shows that the complex is disrupted in a p53- and ER stressdependent fashion. Nevertheless, as the BCL-2/BIK and BiP/BIK complexes are mutually exclusive, it offers an interesting model for how suppression of BiP results in BIK-dependent induction of the apoptotic response. ${ }^{25,26}$
The suppression of $\mathrm{BiP}$ synthesis requires a direct binding between p53 and the 5' of the CDS of the bip mRNA. mRNA translation control by $\mathrm{p} 53$ has previously been reported but this is the first report that links p53 mRNA binding and translation control to specific cell biological and physiological effects. ${ }^{41-45}$ The lack of apparent sequence homology among the mRNAs implicated as targets for p53 transsuppression activity add more evidence to the idea that 
p53 binding to RNA depends on structure rather than sequence. ${ }^{50,51}$

The suppression of $\mathrm{BiP}$ expression requires a 7-aa transsuppressor domain of p53 containing an amphipathic $\alpha$-helical structure located right after the initiation site of p53 $\Delta \mathrm{N} 40$ (aa 40-47). ${ }^{52,53}$ This domain was reported to bind replication protein $A(R P A)^{52}$ and the p62 and Tfb1 subunits of human and yeast $\mathrm{TFIIH}$, respectively, ${ }^{53}$ and it is plausible that the a

bik mRNA expression: $\mathrm{H} 1299$

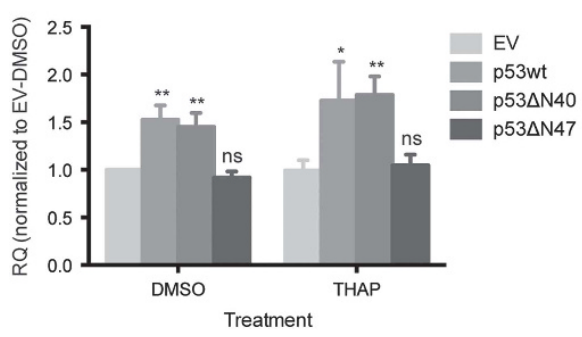

c

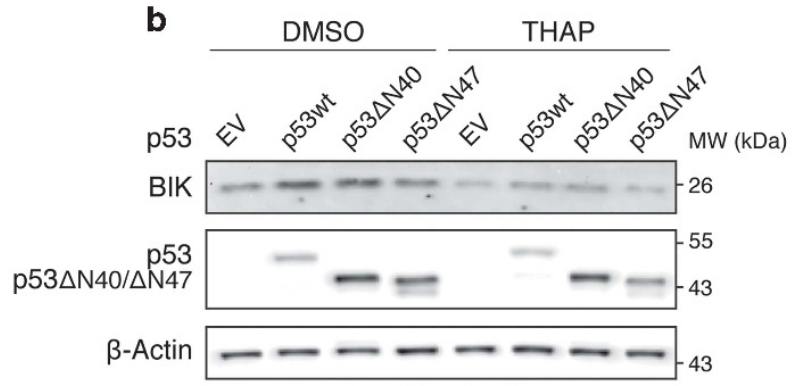

IF

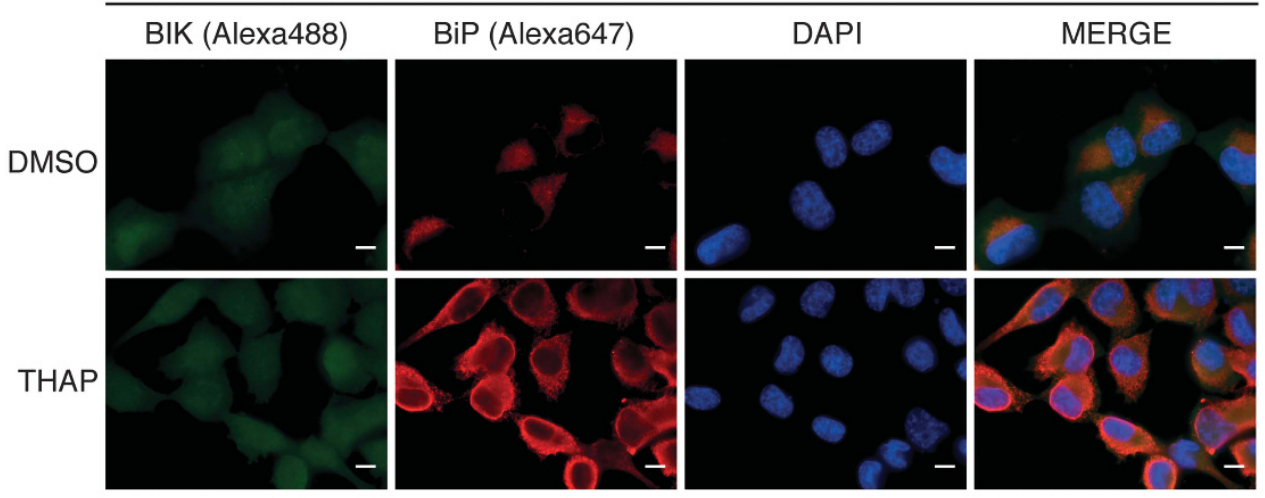

d

PLA: BIK/BiP

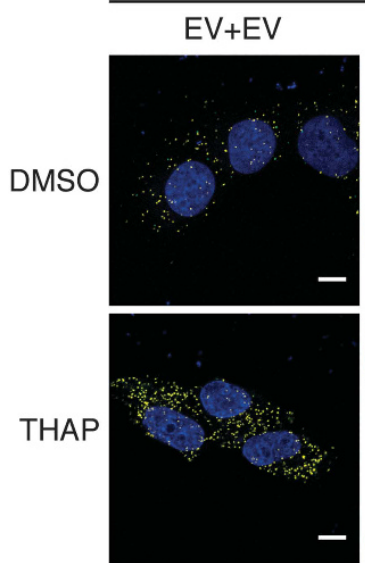

$\mathrm{EV}+\mathrm{EV}$
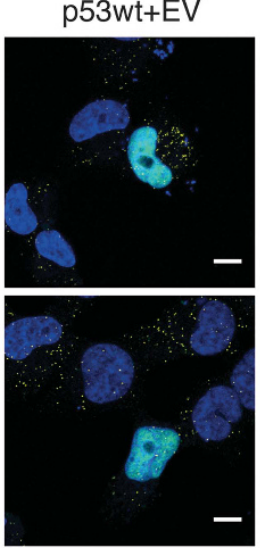

p53wt+EV
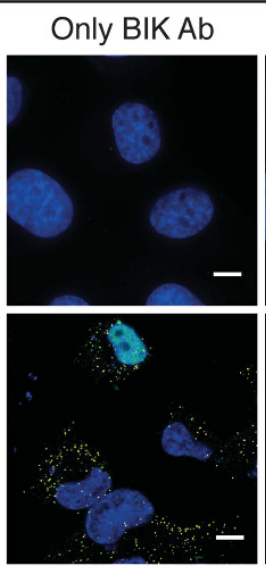

p53wt+BiP(50ng)
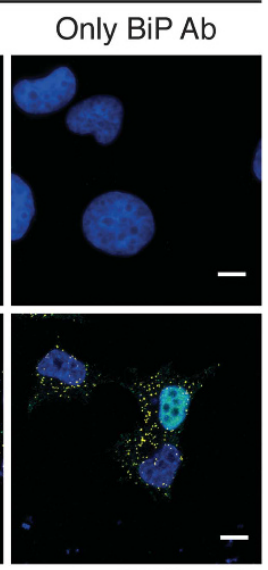

p53wt+BiP(100g)

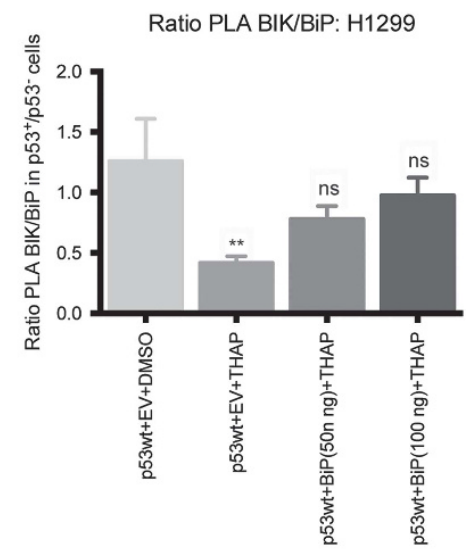

Figure 7 p53-mediated suppression of BiP dissociates the BIK/BiP complex during prolonged ER stress. (a) Quantification of endogenous bik mRNA by relative RT-qPCR. $\mathrm{H} 1299$ cells expressing indicated p53 constructs and treated with $50 \mathrm{nM}$ thapsigargin (THAP) or DMSO for $24 \mathrm{~h}$. Values were normalized against $\beta$-actin and are presented as fold change relative to EV-transfected and DMSO-treated cells, set to 1 (mean \pm S.D., $n=3$ performed in duplicates). Two-tailed paired $t$-test compared data with the corresponding EV-transfected cells, ${ }^{*} P<0.05,{ }^{\star \star} P<0.01$; ns, non-significant. (b) BIK protein levels analyzed by western blotting. Same samples as in Figure 7 a were used to detect endogenous BIK protein. Blots represent $n=3$. (c) IF of endogenous BIK (green, Alexa488) and BiP (red, Alexa647) proteins in H1299 cells treated as in Figure 7a. The scale bar corresponds to $10 \mu \mathrm{m}$. Images are representative of $n \geq 10$ cells obtained in two independent experiments. (d) PLA of endogenous BIK and BiP (yellow dots) in H1299 cells expressing increasing amounts of BiP in normal and in $\mathrm{ER}$ stress conditions using anti-BIK mouse monoclonal and anti-BiP polyclonal antibodies. BiP(50 ng) and BiP (100 ng) refer to 50 and $100 \mathrm{ng}$ of transfected BiP, respectively. p53 expression was detected by IF using p53 monoclonal antibody 1801 labeled with Alexa Fluor 488 . The scale bar corresponds to $10 \mu \mathrm{m}$. Images are representative of $n \geq 10$ cells obtained in three independent experiments. Histogram shows quantification of BIK/BiP PLA complexes as ratio \pm S.D. of PLA dots in p53-expressing divided by dots in p53-negative cells captured as a pair in the same image. 5 images were considered in each case. Two-tailed paired $t$-test compared data to the p53wt-EV-DMSO condition, ${ }^{* *} P<0.01$; ns, non-significant 
trans-suppressive activity of p53 depends on a yet unknown factor binding this domain.

The capacity of $\mathrm{p} 53 \Delta \mathrm{N} 40$ to induce transcription of Bik further adds to the notion that the TAD I (aa 1 to 40) and TAD II (aa 40 to 60) domains of p53 have different cell biological effects under different cellular conditions. The TAD I is associated with the control of $\mathrm{G} 1$ cell cycle progression and p53 lacking TAD I are unable to trans-activate p21 ${ }^{C D K N 1 A} .40,54,55$ On the other hand, the TAD II impinges on apoptosis-related genes as supported by the induction of $B a x^{56}$ and here on Bik. In addition, p53 $\Delta$ N40-dependent induction of Fas, Dr5, Api1 and Pig3 upon exposure to a variety of stress signals also promote apoptosis. ${ }^{55}$

These data suggest a model whereby p53 induces the expression of BIK while at the same time inhibits the induction of $\mathrm{BiP}$ and together, this promotes the dissociation of the BIK/BiP complex following ER stress. This sheds light on the pro-apoptotic pathway during prolonged ER stress and offers new therapeutic approaches to sensitize tumor cells suffering from ER stress for apoptosis induction.

Finally, the capacity of $p 53$ to induce $\mathrm{G} 2$ cell cycle arrest during the UPR depends on suppression of $p 21^{C D K N 1 A}$ mRNA translation. ${ }^{40}$ This, together with the effect described here, strengthens the notion that mRNA translation has a more important role in p53 activity during the ER stress response, as compared with its transcription regulatory activity during the DNA damage response.

\section{Materials and Methods}

Cell culture. p53-positive HCT116 (colon carcinoma) and A549 (lung carcinoma) or p53-null H1299 (non-small cell lung carcinoma) and Saos-2 (osteosarcoma) human cell lines were used. HCT116 cells were kindly provided by Professor B. Vogelstein (Johns Hopkins University, Baltimore, MD, USA). Other cell lines were purchased from the American Type Culture Collection (Manassas, VA, USA). H1299 and Saos-2 cells were cultured in RPMI 1640 medium (no glutamine), HCT116 cells in McCoy's 5 A medium (modified, GlutaMAX) and A549 cells in Dulbecco's modified Eagle's medium medium (high glucose, no glutamine). All media (Gibco, Waltham, MA, USA) were supplemented with $10 \%$ fetal bovine serum (Gibco), $100 \mathrm{U} / \mathrm{ml}$ penicillin and $100 \mathrm{mg} / \mathrm{ml}$ streptomycin (Gibco) and $2 \mathrm{mM}$ L-glutamine (Gibco), except for McCoy's 5 A; L-glutamine was not added. Cell lines were maintained at $37^{\circ} \mathrm{C}$ in an humidified $5 \% \mathrm{CO}_{2}$ incubator. All experiments were performed using exponentially growing cells and cell counts were carried out using a Malassez hemocytometer.

Cell transfection and treatment. Twenty-four hours before transfection, $1.75 \times 10^{5}$ cells were seeded in each well of a six-well plate for most experiments, $7.5 \times 10^{5}$ cells in $10-\mathrm{cm}$ diameter plates for metabolic pulse labeling and $1.5 \times 10^{4}$ cells in each well of a 24-well plate for Proximity Ligation Assay and Immunofluorescence. cDNA transfections were made using GeneJuice reagent (Millipore, Darmstadt, Germany) following manufacturer's protocol and empty vector was added when needed to keep constant the total amount of transfected DNA. If indicated, after $8 \mathrm{~h}$, medium was replaced for siRNA transfection. siRNAs targeting $\mathrm{BiP}, \mathrm{BIK}, \mathrm{CHOP}$ or p53 and AllStars negative control siRNA (Qiagen, Valencia, CA, USA) were transfected using HiPerFect reagent (Qiagen) following manufacturer's instructions. Efficiency of siRNAs was assessed by western blot analysis. Cells were further incubated for $24 \mathrm{~h}$ before treatment. Cells were treated with $50 \mathrm{nM}$ thapsigargin (THAP, Sigma-Aldrich, St. Louis, MO, USA), $7.5 \mathrm{mg} / \mathrm{ml}$ tunicamycin (TUN, Sigma-Aldrich) prepared in DMSO (Euromedex, Strasbourg, France) or $0.1 \%$ DMSO (Euromedex) for $24 \mathrm{~h}$ unless specified otherwise.

Expression vectors. All constructs were in pcDNA3 (Life Technologies, Carlsbad, CA, USA) unless otherwise indicated. p53wt and p53 $\mathrm{N} 40$ (p53/47) constructs have been described previously ${ }^{9,40}$ and are schematically represented in Figure 4a. p53wt codes for both p53 full-length (p53FL) and p53 N N40 isoforms.
Site-directed mutagenesis was performed to clone p $53 \Delta N 47$ by deleting the aa 2-8 from $p 53 \Delta$ N40. The BiP construct was made by amplifying the BiP's ORF from total mRNA extracted from $\mathrm{H} 1299$ cells, retro-transcribed using oligo(dT) 12-18 $_{\text {primer (Life }}$ Technologies) and then amplified by PCR using restriction sites-containing primers flanking the ORF of BiP. The HA-BiP plasmid was obtained by PCR amplification from the above-mentioned BiP with the forward primer containing the HA-tag ( ATGTACCCATACGATGTTCCAGATTACGCT). The constructs carrying bip mRNA segments +1 to $+982,+983$ to $+1965,+1$ to $+491,+492$ to +982 and +1 to +346 were generated by amplification using specific primers and the BiP construct and subcloned into pCDNA3 and are schematically represented in Figure $5 \mathrm{~b}$. bip (1-346)-GFP ( +1 to +346 of bip mRNA) reporter construct was made as follows: GFP ORF was amplified from pEGFP-N1 vector (Clontech, Mountain View, CA, USA) and was inserted into pCDNA3. The first 346-nt of the above-mentioned BiP construct were amplified and cloned up-stream of GFP's ORF in-frame and subsequently, the in-frame Met codons 1 and 9 of BiP were converted into Ala (GCG) codons by sitedirected mutagenesis. bip(346-1965)-GFP (+346 to +1965 of bip mRNA) was generated by amplification with specific primers from the BiP construct and subcloned into pcDNA3 up-stream of GFP as for the previous construct.

Western blotting. Cells were lysed in lysis buffer $(20 \mathrm{mM} H E P E S \mathrm{KOH} \mathrm{pH} 7.5$, $50 \mathrm{mM} \beta$-glycerophosphate, $1 \mathrm{mM}$ EDTA pH 8.0, 1 mM EGTA pH 8.0, $0.5 \mathrm{mM}$ $\mathrm{Na}_{3} \mathrm{VO}_{4} 100 \mathrm{mM} \mathrm{KCl}, 10 \%$ glycerol and $1 \%$ Triton X-100) supplemented with complete protease inhibitor cocktail (Roche, Basel, Switzerland). Protein concentration was determined using Bradford reagent (Bio-Rad, Hercules, CA, USA) and equal protein amounts were separated by NuPAGE gel electrophoresis (Life technologies). After electrophoretic transfer to BioTrace NT pure nitrocellulose blotting membrane (PALL, NY, USA), membranes were blocked with $5 \%$ non-fat dry milk in Tris-buffered saline $\mathrm{pH} 7.6$ containing $0.1 \%$ Tween-20. Proteins were probed by overnight (ON) incubation at $4{ }^{\circ} \mathrm{C}$ with the following antibodies: Anti-HA-tag mouse monoclonal antibody (mAb), anti-p53 CM-1 and ACMDD rabbit polyclonal antibodies (pAbs) were kindly provided by Dr. B. Vojtesek (Masaryk Memorial Cancer Institute, Brno, Czech Republic). For the ACMDD sera raised against the N-terminus of p53 $\mathrm{N} 40$, the membranes were pre-incubated with $0.4 \%$ paraformaldehyde (PFA) at room temperature for $1 \mathrm{~h}$ and washed with water (Gibco) (three times for $5 \mathrm{~min}$ ) before blocking. Anti-cleaved PARP-1 rabbit pAb was from Cell Signaling Technology (Danvers, MA, USA), anti-BiP rabbit pAb and anti-CHOP mouse mAb were purchased from Abcam (Cambridge, UK), anti-BIK mouse mAb and anti-PARP-1 rabbit pAb were purchased from Santa Cruz (Dallas, TX, USA), anti- $\beta$-actin mouse mAbs were purchased from Sigma-Aldrich, anti-GFP mouse mAb was purchased from Roche. Membranes were then incubated with appropriate HRP-conjugated secondary antibodies (Dako, Glostrup, Denmark) and detection was performed using WestDura (Thermo Fisher Scientific, Waltham, MA, USA) and either Hyperfilm (GE Healthcare, Little Chalfont, UK), CHEMI-SMART 5000 documentation system and Chemi-Capt software (Vilbert Lourmat, Eberhardzell, Germany) or myECL Imager and mylmage Analysis software (Thermo Fisher Scientific). The two latter were used for protein bands quantification by densitometry analysis performed with either Bio-PROFIL Bio 1D software (Vilbert Lourmat) or ImageJ.

Apoptosis assay. Both floating and attached cells were collected $24 \mathrm{~h}$ following DMSO or THAP treatment for HCT116 and H1299. Cells were then simultaneously stained with Annexin V-FITC and PI using the Annexin V-FITC Apoptosis Detection Kit from Sigma-Aldrich, as per manufacturer's instructions. Annexin V binds to exposed phosphatidylserines on early apoptotic cells, whereas the non-vital dye propidium iodide (PI) stains late apoptotic and necrotic cells. Counting of cells was performed for 20000 events using BD FACSCanto II flow cytometer and analysis was carried out with BD FACSDiva software (BD Biosciences, San Jose, CA, USA).

RNA extraction, reverse transcription and RT-qPCR. Total RNA was extracted with RNeasy Mini Kit (Qiagen) following manufacturer's instructions. cDNA synthesis was carried out using the Moloney murine leukaemia virus reverse transcriptase and Oligo(dT) ${ }_{12-18}$ primer (Life technologies). RT-qPCR was performed by the StepOne real-time PCR system (Applied Biosystems, Foster City, CA, USA) using Perfecta SYBR Green FastMix, ROX (Quanta Biosciences, Beverly, MA, USA) and the following primers: BiP-F $5^{\prime}$ GCAACCAAAGACGCTGGAACT3', BiP-R 5'CCTCCCTCTTATCCAGGCCATA3', HA-BiP-F 5'CCCATACGATGTTCCAGATTA CG3', HA-BIP-R 5'CCCACGTCCTCCTTCTTGTC3', BIK-F 5'CCTGCACCTGCT GCTCAAG3', BIK-R 5'ACCTCAGGGCAGTGGTCATG3', EGFP-F 5'CATGCCCGA AGGCTACGTC3', EGFP-R 5'TCAGCTCGATGCGGTTCACC $3^{\prime}, \beta$-Actin-F 5'TCAC 
CCACACTGTGCCCATCTACGA3' and $\beta$-Actin-R 5'TGAGGTAGTCAGTCAGGTC CCG3'.

Metabolic radiolabelling and immunoprecipitation. After seeding, transfection and treatment, cells were kept at $37^{\circ} \mathrm{C}$ and $5 \% \mathrm{CO}_{2}$ in Dulbecco's modified Eagle's starvation medium (not including methionine, cystine and L-glutamine, Sigma-Aldrich) supplemented with $2 \%$ fetal bovine serum dialysed against PBS (Gibco), $2 \mathrm{mM}$ L-glutamine, $100 \mathrm{U} / \mathrm{ml}$ penicillin and $100 \mathrm{mg} / \mathrm{ml}$ streptomycin, and DMSO or THAP for $1.5 \mathrm{~h}$ together with $25 \mu \mathrm{M}$ of the proteasome inhibitor MG132 (Calbiochem, San Diego, CA, USA) for the final $50 \mathrm{~min}$. Cells were metabolically radiolabelled with $45 \mu \mathrm{Ci} / \mathrm{ml}$ of EasyTag Express ${ }^{35} \mathrm{~S}$-methionine Protein Labeling Mix (PerkinElmer, Waltham, MA, USA) during the final $20 \mathrm{~min}$. Cells were lysed in lysis buffer (20 mM Tris- $\mathrm{HCl}, \mathrm{pH} 7.5,150 \mathrm{mM} \mathrm{NaCl}$ and 1\% NP-40) supplemented with complete protease inhibitor cocktail (Roche). Equal protein amounts, as determined by Bradford (Bio-Rad), were pre-cleared with rabbit or mouse serum (Dako) and Dynabeads Protein G (Life Technologies). Samples were immunoprecipitated by overnight incubation with anti-BiP rabbit pAb (Abcam), antiHA-tag mouse mAB (provided by Dr. B. Vojtesek) or non-specific mouse lgG antibody (Jackson ImmunoResearch Laboratories, West Grove, PA, USA) at $4{ }^{\circ} \mathrm{C}$ and beads that were added $2 \mathrm{~h}$ after the Abs. Beads were washed and boiled in $2 \mathrm{X}$ Laemmli buffer. Proteins were resolved in NuPAGE gel electrophoresis (Life Technologies) fixed in $7 \%$ methanol and $20 \%$ acetic acid and the signal was amplified by incubation with Amplify (GE Healthcare). Finally, gels were dried. Detection was achieved by exposure to X-ray film. Autoradiography of input samples confirmed equal incorporation of overall ${ }^{35} \mathrm{~S}$-methionine into cellular proteins. For quantification of immunoprecipitated radiolabelled proteins, gels were exposed to phosphor imager screen, scanned using a Storm 840 phosphorimager (Molecular Dynamics, GE Healthcare) and analyzed with Image-Quant software (Molecular Dynamics, GE Healthcare).

In vitro translation. $\mathrm{N}$-terminal His-tagged full-length p53 was cloned into pET-28a (Novagen, Madison, WI, USA) and was expressed in BL21(DE3) Escherichia coli. Lysis was performed with $25 \mathrm{mM}$ Hepes pH 8.0, $100 \mathrm{mM} \mathrm{NaCl}, 1 \mathrm{mM}$ Tris, $20 \mathrm{mM}$ imidazole, $10 \%$ glycerol, $10 \mu \mathrm{M} \mathrm{ZnSO}_{4}$ supplemented with protease inhibitor cocktail EDTA-free (Roche). p53 was then purified with HisTrap HP $1 \mathrm{~mL}$ columns (GE Healthcare) and ÄKTApurifier 10 (GE Healthcare) as per manufacturer's instructions. bip and gfp mRNAs were in vitro-synthesized and capped with mMESSAGE mMACHINE T7 kit (Ambion, Carlsbad, CA, USA) following manufacturer's instructions and using as template the linearized PCDNA3 containing either BiP or GFP sequences (described above). Both bip and gfp mRNAs ( $400 \mathrm{ng}$ of each) in the same reaction, along with $0.5 \mu \mathrm{M}$ of partially-purified p53 protein were pre-incubated in binding buffer containing $50 \mathrm{mM}$ Tris pH 7.5, $150 \mathrm{mM} \mathrm{NaCl}$, $0.02 \mu \mathrm{g} / \mathrm{ml}$ yeast tRNA (Ambion), $0.2 \mathrm{mg} / \mathrm{ml}$ BSA (Sigma-Aldrich) for $15 \mathrm{~min}$ at $37^{\circ} \mathrm{C}$. In vitro translation assays were performed with $41 \mu \mathrm{Ci} / \mathrm{ml}$ of Easytag Express Protein Methionine Mix (PerkinElmer) and Reticulocyte Lysate system (Promega, Madison, WI, USA) according to the manufacturer's protocol for $1.5 \mathrm{~h}$ at $30^{\circ} \mathrm{C}$ and boiled in 2X Laemmli buffer. Proteins were resolved by NuPAGE gel electrophoresis (Life Technologies), followed by fixation, amplification and drying of the gels. Detection was achieved by exposure to X-ray film (GE Healthcare).

In vitro protein-RNA co-immunoprecipitation. p53-purified protein (see before) was used. In addition to bip FL mRNA, segments +1 to $+982,+983$ to $+1965,+1$ to $+491,+492$ to +982 and +1 to +346 were synthesized as described. All binding reactions were carried out for $15 \mathrm{~min}$ at $37^{\circ} \mathrm{C}$ in binding buffer containing $50 \mathrm{mM}$ Tris pH 7.5, $150 \mathrm{mM} \mathrm{NaCl}, 0.02 \mu \mathrm{g} / \mathrm{ml}$ yeast tRNA, $0.2 \mathrm{mg} / \mathrm{ml}$ BSA. $120 \mathrm{ng}$ of recombinant p53 protein and a fixed amount $(0.01 \mathrm{pmol})$ of different bip mRNAs were used. After incubation, RNA-protein complexes were pulled-down ON at $4{ }^{\circ} \mathrm{C}$ using anti-p53 DO-12 mouse mAb kindly provided by Dr. B. Vojtesek and protein G sepharose Fast Flow (Sigma-Aldrich). The unbound fraction was recovered for later analysis and the bound RNA was released from the beads using proteinase $K$ (Sigma-Aldrich) for $30 \mathrm{~min}$ at $55^{\circ} \mathrm{C}$. All RNA fractions were then extracted and purified using the TRIzol protocol (Life Technologies). RT-qPCR was performed using primers for the following segments: FL $(+1$ to +1965$),+1$ to $+982,+492$ to +982; same primers used for qPCR, +983 to +1965; F 5'GTCCCACAGATTG

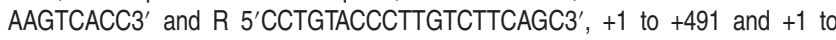
+346; F 5'CACGCCGTCCTATGTCGC3' and R 5'TGTTCTCGGGGTTGGAGG3', +1 to +246; F 5'GGCCGCGTGGAGATCATC3' and R 5'GGCGGCATCGCCAA TCAG3'. The relative binding of each $\mathrm{mRNA}$ to proteins was expressed as the ratio of bound to total (bound+free) RNA.
IF and PLA. For IF of proteins, following seeding, transfection and treatment, coverslips with cells were briefly washed with PBS and fixed with 4\% PFA for 20 min at RT, washed again with PBS and blocked with blocking buffer (PBS 3\% BSA, 0.1\% saponin) for $30 \mathrm{~min}$ at RT. Primary Abs were diluted in blocking buffer, 1:500 for antip53 CM-1 rabbit pAb, $10 \mu \mathrm{g} / \mathrm{ml}$ for anti-BiP rabbit pAb (Abcam) and $1.5 \mu \mathrm{g} / \mathrm{ml}$ for antiBIK mouse mAb (Santa Cruz) and incubated in a wet chamber for 90 min at RT. After several washes with PBS, goat secondary Abs anti-mouse IgG-Alexa488 and antirabbit IgG-Alexa647 (Molecular Probes, Life Technologies) diluted 1:500 into blocking buffer were added and incubated in a wet chamber for $45 \mathrm{~min}$ at RT. Finally, samples were stained with $50 \mathrm{ng} / \mathrm{ml}$ DAPI (Sigma-Aldrich) in PBS for $5 \mathrm{~min}$ at RT and washed with PBS at RT before mounting. For the protein-protein PLA, samples were treated as for IF until primary antibody incubation. After that, DuoLink II PLA kit (Sigma-Aldrich) was used following manufacturer's instructions using custom solutions, followed by DAPI staining, washing with PBS and mounting. For the protein-protein PLA coupled to IF against p53, following PLA amplification samples were washed with PLA buffer $B$ for 5 min at RT, incubated with 1:250 dilution of anti-p53-Alexa488 mouse mAb 1801 (Abcam) in blocking buffer for 40 min in wet chamber at RT, stained with DAPI in buffer $B$ for 5 min at RT, washed with buffer B, rinsed with $0.01 \times$ buffer $B$ and mounted. In protein-RNA PLA or RNA IF, cover-slips with cells were briefly washed with PBS and fixed with 4\% PFA for $20 \mathrm{~min}$ at RT, washed again with PBS and incubated in 70\% ethanol for $6 \mathrm{~h}$ at $4{ }^{\circ} \mathrm{C}$. Samples were re-hydrated with PBS for $30 \mathrm{~min}$ at RT, permeabilized with $0.4 \%$ Triton X-100, $0.05 \%$ CHAPS in PBS for 5 min at RT, washed with PBS, incubated in hybridization buffer ( $2 \times \mathrm{SSC}, 0.2 \mathrm{mg} / \mathrm{ml} E$. coli tRNA (Roche), $0.2 \mathrm{mg} / \mathrm{ml}$ sheared salmon sperm DNA (Life Technologies), $2 \mathrm{mg} / \mathrm{ml} \mathrm{BSA} \mathrm{(Sigma-}$ Aldrich)) in a wet chamber for $30 \mathrm{~min}$ at RT and hybridized with $50 \mathrm{ng}$ of DNA probe coupled to digoxigenin at its $3^{\prime}$ (previously denatured at $80^{\circ} \mathrm{C}$ for $5 \mathrm{~min}$ ) in hybridization buffer in wet chamber $\mathrm{ON}$ at $37^{\circ} \mathrm{C}$. Anti-bip DNA probe $5^{\prime} \mathrm{CTG}$ GACGGGCTTCATAGTAGAAAAA3'-DIG and anti-gfp DNA probe 5' AGGATGTT GCCGTCCTCCTTGAAGTCGAAAAA3'-DIG were used (Eurogentec, Liège, Belgium). Samples were briefly washed with wash buffer (2X SSC, 10\% formamide), further washed twice with hybridization buffer for $20 \mathrm{~min}$ and once with PBS for $20 \mathrm{~min}$ at $37^{\circ} \mathrm{C}$, followed by the above-described PLA and IF protocols using 1:200 dilution of anti-digoxigenin mouse mAb (Sigma-Aldrich) and 1:500 for anti-p53 CM-1 rabbit pAb in blocking buffer. Images were obtained either with Axiovert 200M microscopy and AxioVision software (Carl Zeiss Vision, Oberkochen, Germany) or LSM 800 airyscan confocal microscopy and Zen 2.1 (blue edition) software (Carl Zeiss Microscopy $\mathrm{GmbH}$, Oberkochen, Germany). Number of PLA BIK/BiP complexes were quantified using ImageJ in pairs of p53-positive and p53-negative cells and a ratio was calculated.

Statistical analysis. Data shown represent the mean \pm S.D. (unless specified otherwise) of minimum three independent experiments. Two-tailed paired and unpaired Student's $t$-test were performed by comparing data to the corresponding reference point or as indicated and two-way ANOVA was used when different groups of samples were compared. $P$-values are shown on graphs. ${ }^{*} P<0.05$; ${ }^{\star \star} P<0.01 ;{ }^{* \star} P<0.001$; ns, not significant.

\section{Conflict of Interest}

The authors declare no conflict of interest.

Acknowledgements. This work was supported by la Ligue Contre le Cancer, the Inserm and the projects INCA_9413, GACR P206/12/G151 and MEYS-NPS I-L01413. I.L. was supported by AXA Research Fund and Fondation pour la Recherche Médicale FRM (FDT20150532276). A-S.T. was supported by PACRI. R.P. M. was supported by Institut National du Cancer (INCA_10683). K.K. was supported by Institut National du Cancer (INCA_9413). We greatly thank the members of the Plateforme Technologique from the Institut Universitaire d'Hématologie (IUH), Paris, France for their valuable technical assistance.

1. Behnke J, Feige MJ, Hendershot LM. BiP and its nucleotide exchange factors Grp170 and Sil1: mechanisms of action and biological functions. J Mol Biol 2015; 427: 1589-1608.

2. Morito D, Nagata K. Pathogenic hijacking of ER-associated degradation: is ERAD flexible? Mol Cell 2015; 59: 335-344.

3. Hetz $\mathrm{C}$, Chevet E, Harding HP. Targeting the unfolded protein response in disease. Nat Rev Drug Discov 2013; 12: 703-719.

4. Calfon M, Zeng H, Urano F, Till JH, Hubbard SR, Harding HP et al. IRE1 couples endoplasmic reticulum load to secretory capacity by processing the XBP-1 mRNA. Nature 2002; 415: 92-96. 
5. Lee K, Tirasophon W, Shen X, Michalak M, Prywes R, Okada T et al. IRE1-mediated unconventional mRNA splicing and S2P-mediated ATF6 cleavage merge to regulate XBP1 in signaling the unfolded protein response. Genes Dev 2002; 16: 452-466.

6. Yoshida H, Matsui T, Yamamoto A, Okada T, Mori K. XBP1 mRNA is induced by ATF6 and spliced by IRE1 in response to ER stress to produce a highly active transcription factor. Cell 2001; 107: 881-891.

7. Hollien J, Weissman JS. Decay of endoplasmic reticulum-localized mRNAs during the unfolded protein response. Science 2006; 313: 104-107.

8. Jackson RJ, Hellen CU, Pestova TV. The mechanism of eukaryotic translation initiation and principles of its regulation. Nat Rev Mol Cell Biol 2010; 11: 113-127.

9. Bourougaa K, Naski N, Boularan C, Mlynarczyk C, Candeias MM, Marullo S et al. Endoplasmic reticulum stress induces $\mathrm{G} 2$ cell-cycle arrest via mRNA translation of the p53 isoform p53/47. Mol Cell 2010; 38: 78-88.

10. Harding HP, Novoa I, Zhang Y, Zeng H, Wek R, Schapira M et al. Regulated translation initiation controls stress-induced gene expression in mammalian cells. Mol Cell 2000; 6: 1099-1108.

11. Vattem KM, Wek RC. Reinitiation involving upstream ORFs regulates ATF4 mRNA translation in mammalian cells. Proc Natl Acad Sci USA 2004; 101: 11269-11274.

12. Haze K, Yoshida H, Yanagi H, Yura T, Mori K. Mammalian transcription factor ATF6 is synthesized as a transmembrane protein and activated by proteolysis in response to endoplasmic reticulum stress. Mol Biol Cell 1999; 10: 3787-3799.

13. Lee AS. Glucose-regulated proteins in cancer: molecular mechanisms and therapeutic potential. Nat Rev Cancer 2014; 14: 263-276.

14. Yoshida H, Haze K, Yanagi H, Yura T, Mori K. Identification of the cis-acting endoplasmic reticulum stress response element responsible for transcriptional induction of mammalian glucose-regulated proteins. Involvement of basic leucine zipper transcription factors. J Biol Chem 1998; 273: 33741-33749.

15. Oyadomari S, Mori M. Roles of CHOP/GADD153 in endoplasmic reticulum stress. Cell Death Differ 2004; 11: 381-389.

16. Urra H, Dufey E, Lisbona F, Rojas-Rivera D, Hetz C. When ER stress reaches a dead end. Biochim Biophys Acta 2013; 1833: 3507-3517.

17. Zinszner H, Kuroda M, Wang X, Batchvarova N, Lightfoot RT, Remotti $\mathrm{H}$ et al. CHOP is implicated in programmed cell death in response to impaired function of the endoplasmic reticulum. Genes Dev 1998; 12: 982-995.

18. Bertolotti A, Zhang Y, Hendershot LM, Harding HP, Ron D. Dynamic interaction of BiP and ER stress transducers in the unfolded-protein response. Nat Cell Biol 2000; 2: 326-332.

19. Shen J, Chen X, Hendershot L, Prywes R. ER stress regulation of ATF6 localization by dissociation of BiP/GRP78 binding and unmasking of Golgi localization signals. Dev Cell 2002; 3: 99-111.

20. Gulow K, Bienert D, Haas IG. BiP is feed-back regulated by control of protein translation efficiency. J Cell Sci 2002; 115: 2443-2452.

21. Macejak DG, Sarnow P. Internal initiation of translation mediated by the $5^{\prime}$ leader of a cellular mRNA. Nature 1991; 353: 90-94.

22. Starck SR, Tsai JC, Chen K, Shodiya M, Wang L, Yahiro K et al. Translation from the $5^{\prime}$ untranslated region shapes the integrated stress response. Science 2016; 351: aad3867.

23. Luo S, Mao C, Lee B, Lee AS. GRP78/BiP is required for cell proliferation and protecting the inner cell mass from apoptosis during early mouse embryonic development. Mol Cell Biol 2006; 26: 5688-5697.

24. Rao RV, Peel A, Logvinova A, del Rio G, Hermel E, Yokota T et al. Coupling endoplasmic reticulum stress to the cell death program: role of the ER chaperone GRP78. FEBS Lett 2002; 514: 122-128.

25. Fu Y, Li J, Lee AS. GRP78/BiP inhibits endoplasmic reticulum BIK and protects human breast cancer cells against estrogen starvation-induced apoptosis. Cancer Res 2007; 67: 3734-3740.

26. Zhou H, Zhang Y, Fu Y, Chan L, Lee AS. Novel mechanism of anti-apoptotic function of 78$\mathrm{kDa}$ glucose-regulated protein (GRP78): endocrine resistance factor in breast cancer, through release of B-cell lymphoma 2 (BCL-2) from BCL-2-interacting killer (BIK). J Biol Chem 2011; 286: 25687-25696.

27. Chinnadurai G, Vijayalingam S, Rashmi R. BIK the founding member of the BH3-only family proteins: mechanisms of cell death and role in cancer and pathogenic processes. Oncogene 2008; 27: S20-S29.

28. Wilfling F, Weber A, Potthoff S, Vogtle FN, Meisinger C, Paschen SA et al. BH3-only proteins are tail-anchored in the outer mitochondrial membrane and can initiate the activation of Bax. Cell Death Differ 2012; 19: 1328-1336.

29. Germain M, Mathai JP, Shore GC. BH-3-only BIK functions at the endoplasmic reticulum to stimulate cytochrome c release from mitochondria. J Biol Chem 2002; 277: 18053-18060.

30. Mathai JP, Germain M, Marcellus RC, Shore GC. Induction and endoplasmic reticulum location of BIK/NBK in response to apoptotic signaling by E1A and p53. Oncogene 2002; 21: 2534-2544.

31. Mathai JP, Germain M, Shore GC. BH3-only BIK regulates BAX,BAK-dependent release of $\mathrm{Ca} 2+$ from endoplasmic reticulum stores and mitochondrial apoptosis during stress-induced cell death. J Biol Chem 2005; 280: 23829-23836.

32. Wang $\mathrm{X}$, Olberding KE, White $\mathrm{C}$, Li C. Bcl-2 proteins regulate ER membrane permeability to luminal proteins during ER stress-induced apoptosis. Cell Death Differ 2011; 18: 38-47.

33. Gillissen B, Essmann F, Hemmati PG, Richter A, Richter A, Oztop I et al. Mcl-1 determines the Bax dependency of Nbk/Bik-induced apoptosis. J Cell Biol 2007; 179: 701-715.
34. Chipuk JE, Green DR. Dissecting p53-dependent apoptosis. Cell Death Differ 2006; 13: 994-1002.

35. el-Deiry WS, Harper JW, O'Connor PM, Velculescu VE, Canman CE, Jackman J et al. WAF1/ CIP1 is induced in p53-mediated G1 arrest and apoptosis. Cancer Res 1994; 54: 1169-1174.

36. Kracikova M, Akiri G, George A, Sachidanandam R, Aaronson SA. A threshold mechanism mediates p53 cell fate decision between growth arrest and apoptosis. Cell Death Differ 2013; 20: $576-588$.

37. Miyashita T, Reed JC. Tumor suppressor p53 is a direct transcriptional activator of the human bax gene. Cell 1995; 80: 293-299.

38. Candeias MM, Powell DJ, Roubalova E, Apcher S, Bourougaa K, Vojtesek B et al. Expression of p53 and p53/47 are controlled by alternative mechanisms of messenger RNA translation initiation. Oncogene 2006; 25: 6936-6947.

39. Ray PS, Grover R, Das S. Two internal ribosome entry sites mediate the translation of p53 isoforms. EMBO Rep 2006; 7: 404-410.

40. Mlynarczyk C, Fahraeus R. Endoplasmic reticulum stress sensitizes cells to DNA damageinduced apoptosis through p53-dependent suppression of p21(CDKN1A). Nat Commun 2014; 5 : 5067.

41. Galy B, Creancier L, Prado-Lourenco L, Prats AC, Prats H. p53 directs conformational change and translation initiation blockade of human fibroblast growth factor 2 mRNA. Oncogene 2001; 20: 4613-4620.

42. Galy B, Creancier L, Zanibellato C, Prats AC, Prats H. Tumour suppressor p53 inhibits human fibroblast growth factor 2 expression by a post-transcriptional mechanism. Oncogene 2001; 20: 1669-1677.

43. Miller SJ, Suthiphongchai T, Zambetti GP, Ewen ME. p53 binds selectively to the $5^{\prime}$ untranslated region of cdk4, an RNA element necessary and sufficient for transforming growth factor betaand p53-mediated translational inhibition of cdk4. Mol Cell Biol 2000; 20: 8420-8431.

44. Mosner J, Mummenbrauer T, Bauer C, Sczakiel G, Grosse F, Deppert W. Negative feedback regulation of wild-type p53 biosynthesis. EMBO J 1995; 14: 4442-4449.

45. Tournillon AS, Lopez I, Malbert-Colas L, Findakly S, Naski N, Olivares-Illana V et al. p53 binds the mdmx mRNA and controls its translation. Oncogene 2017; 36: 723-730.

46. Rogers TB, Inesi G, Wade R, Lederer WJ. Use of thapsigargin to study Ca2+ homeostasis in cardiac cells. Biosci Rep 1995; 15: 341-349.

47. Chaitanya GV, Steven AJ, Babu PP. PARP-1 cleavage fragments: signatures of cell-death proteases in neurodegeneration. Cell Commun Signal 2010; 8: 31

48. Tkacz JS, Lampen O. Tunicamycin inhibition of polyisoprenyl $\mathrm{N}$-acetylglucosaminyl pyrophosphate formation in calf-liver microsomes. Biochem Biophys Res Commun 1975; 65: 248-257.

49. Mujtaba T, Dou QP. Advances in the understanding of mechanisms and therapeutic use of bortezomib. Discov Med 2011; 12: 471-480.

50. Riley KJ, Cassiday LA, Kumar A, Maher LJ 3rd. Recognition of RNA by the p53 tumo suppressor protein in the yeast three-hybrid system. RNA 2006; 12: 620-630.

51. Riley KJ, Maher LJ 3rd. p53 RNA interactions: new clues in an old mystery. RNA 2007; 13: 1825-1833.

52. Bochkareva E, Kaustov L, Ayed A, Yi GS, Lu Y, Pineda-Lucena A et al. Single-stranded DNA mimicry in the $\mathrm{p} 53$ transactivation domain interaction with replication protein A. Proc Natl Acad Sci USA 2005; 102: 15412-15417.

53. Di Lello $\mathrm{P}$, Jenkins LM, Jones TN, Nguyen BD, Hara T, Yamaguchi $\mathrm{H}$ et al. Structure of the $\mathrm{Tfb} 1 / \mathrm{p} 53$ complex: Insights into the interaction between the p62/Tfb1 subunit of TFIIH and the activation domain of p53. Mol Cell 2006; 22: 731-740.

54. Ghosh A, Stewart D, Matlashewski G. Regulation of human p53 activity and cell localization by alternative splicing. Mol Cell Biol 2004; 24: 7987-7997.

55. Phang BH, Othman R, Bougeard G, Chia RH, Frebourg T, Tang CL et al. Amino-terminal p53 mutations lead to expression of apoptosis proficient p47 and prognosticate better survival, but predispose to tumorigenesis. Proc Natl Acad Sci USA 2015; 112: E6349-E6358.

56. Yin Y, Stephen CW, Luciani MG, Fahraeus R. p53 Stability and activity is regulated by Mdm2mediated induction of alternative p53 translation products. Nat Cell Biol 2002; 4: 462-467.

57. Lopez I, Tournillon AS, Nylander K, Fahraeus R. p53-mediated control of gene expression via mRNA translation during Endoplasmic Reticulum stress. Cell Cycle 2015; 14: 3373-3378.

(1)(2) This work is licensed under a Creative Commons Attribution-NonCommercial-ShareAlike 4.0 International License. The images or other third party material in this article are
included in the article's Creative Commons license, unless indicated included in the article's Creative Commons license, unless indicated otherwise in the credit line; if the material is not included under the
Creative Commons license, users will need to obtain permission from the license holder to reproduce the material. To view a copy of this license, visit http://creativecommons.org/licenses/by-nc-sa/4.0/

(C) The Author(s) 2017 